Review

\title{
A review on cationic starch and nanocellulose as paper coating components
}

\author{
Mohit Sharma a ${ }^{\text {, Roberto Aguado }}{ }^{\text {,** }}$, Dina Murtinho ${ }^{\text {b }}$, Artur J.M. Valente ${ }^{\text {b }}$, \\ António P. Mendes De Sousa ${ }^{c}$, Paulo J.T. Ferreira ${ }^{a}$ \\ a University of Coimbra, CIEPQPF, Department of Chemical Engineering, Rua Sílvio Lima, Pólo II - Pinhal de Marrocos, 3030-790 Coimbra, Portugal \\ b University of Coimbra, CQC and Department of Chemistry, Rua Larga, 3004-535 Coimbra, Portugal \\ ${ }^{c}$ RAIZ - Institute of Forest and Paper Research, Apartado 15, 3801-501 Eixo, Portugal
}

\section{A R T I C L E I N F O}

\section{Article history:}

Received 20 March 2020

Received in revised form 6 June 2020

Accepted 14 June 2020

Available online 18 June 2020

\section{Keywords:}

Cationic starch

Cellulose nanocrystals

Cellulose nanofibrils

Paper coating

Printing quality

\begin{abstract}
A B S T R A C T
Starch and derivatives thereof have proven their usefulness in paper coating processes. Among these derivatives, cationic starch has been widely used in the paper industry as a flocculation, dispersion and ink fixing agent. In another context, nanoscale cellulosic materials have been shown to improve the strength, retention of fillers, the barrier properties of packaging paper products, and printing qualities. This review summarizes the recent studies on the general components used in paper coating, describes the conventional and alternative synthetic processes of cationic starches and nanocellulose, and deals with their current and potential applications in papermaking, focusing primarily on surface treatments. Moreover, environmental applications have been considered to expand the understanding and usefulness of these materials. Further research on modified polysaccharides is encouraged to replace, in a feasible way, petro-based components of coating formulations, and to provide paper surfaces with new properties.
\end{abstract}

(c) 2020 Elsevier B.V. All rights reserved.

\section{Contents}

1. Introduction $\ldots .579$

2. General components of paper coating formulation . . . . . . . . . . . . . . . . . . . . . . . . . . . . . . 579

2.1. Pigment . . . . . . . . . . . . . . . . . . . . . . . . . . . . . . . . . . . 5 579

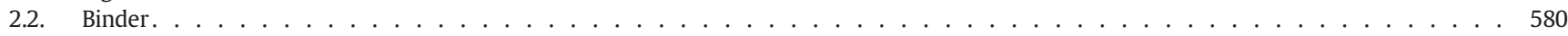

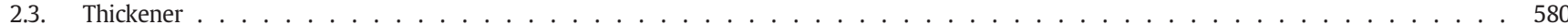

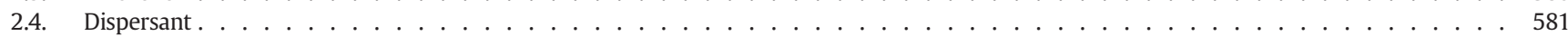

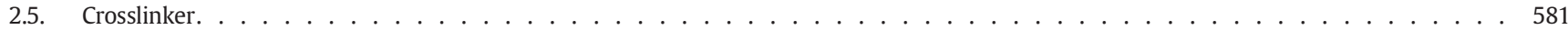

2.6. Optical brightening agent $(\mathrm{OBA}) \ldots \ldots \ldots \ldots \ldots$

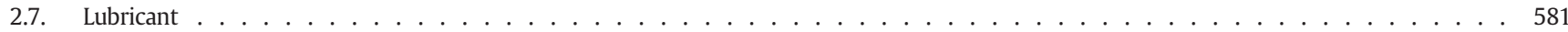

3. Potential of polysaccharides for paper coating . . . . . . . . . . . . . . . . . . . . . . . . . . . . . . . 581

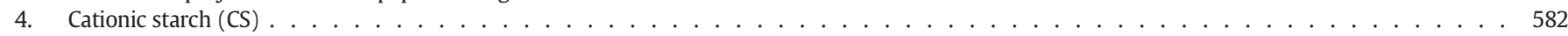

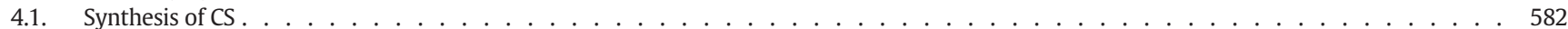

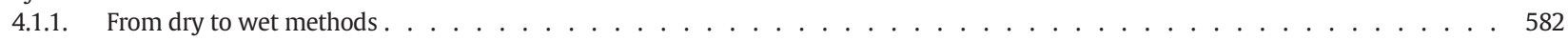

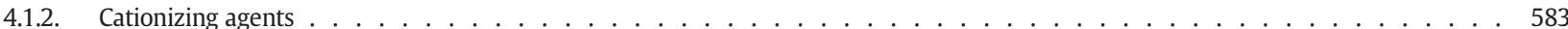

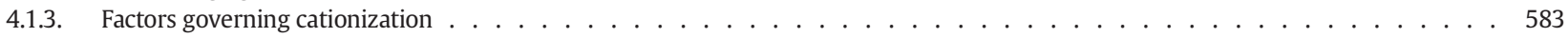

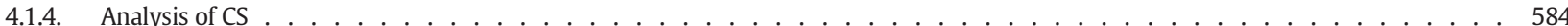

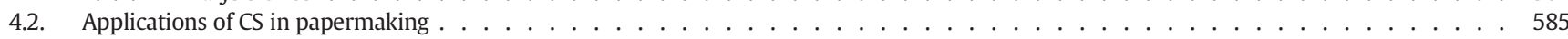

4.2.1. Wet end chemistry . . . . . . . . . . . . . . . . . . . . . . . . . . . 585

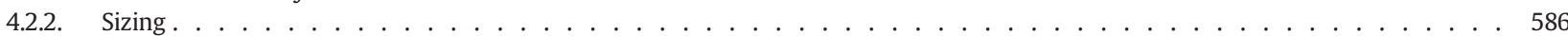

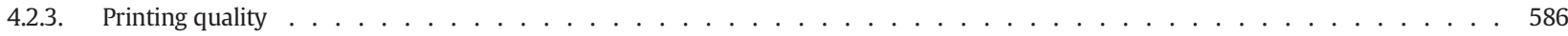

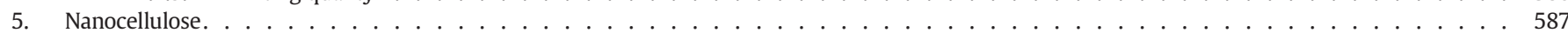

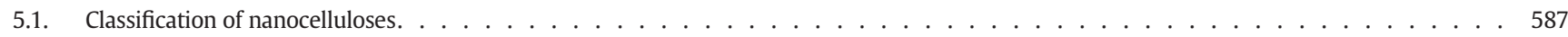

\footnotetext{
* Corresponding author.

E-mail address: rag@uc.pt (R. Aguado).
} 
5.1.1. Cellulose nanofibrils (CNFs) and cellulose microfibrils (CMFs)

5.1.2. Cellulose nanocrystals $(\mathrm{CNCs}) \ldots \ldots \ldots \ldots \ldots$

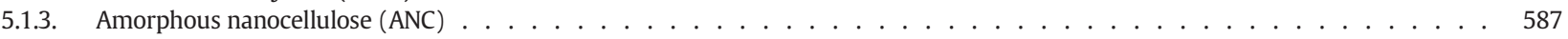

5.1.4. Bacterial cellulose $(\mathrm{BC}) \ldots \ldots \ldots \ldots \ldots \ldots$

5.1.5. Cellulose nanoyarn $(\mathrm{CNY})$ or electrospun nanofibers . . . . . . . . . . . . . . . . . . . . . . . . . . . 588

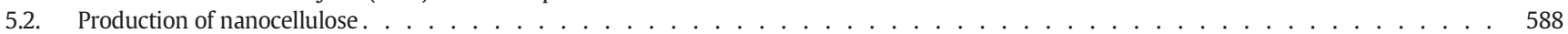

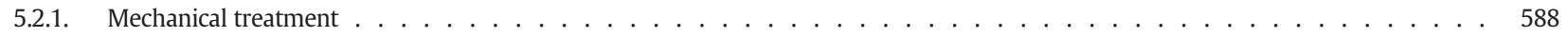

5.2.2. Enzymatic and chemical treatments . . . . . . . . . . . . . . . . . . . . . . . . . . . . . . . . . . . . . . . 589

5.3. Applications of nanocellulose in papermaking. . . . . . . . . . . . . . . . . . . . . . . . . . . . . . . . . . . 590

5.3.1. Wet end chemistry. . . . . . . . . . . . . . . . . . . . . . . . . . . . . . 591

5.3.2. Paper coating . . . . . . . . . . . . . . . . . . . . . . . . . . . . . . . . . 591

6. Technical, economic, environmental and legal considerations . . . . . . . . . . . . . . . . . . . . . . . . . . . . . 592

6.1. Technical feasibility of surface treatments with nanocellulose and cationic starch . . . . . . . . . . . . . . . . . . . . . . 592

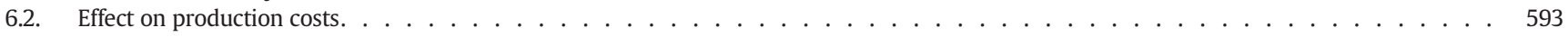

6.3. Environmental impact . . . . . . . . . . . . . . . . . . . . . . . . . . . . . . . . . . . . 593

6.4. European legislation . . . . . . . . . . . . . . . . . . . . . . . . . . . . . . . . . . . . . . . . 594

7. Challenges and future perspectives . . . . . . . . . . . . . . . . . . . . . . . . . . . . $\ldots$

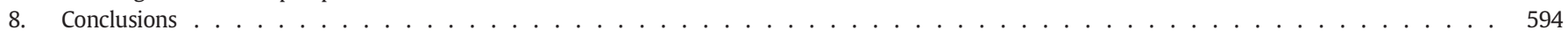

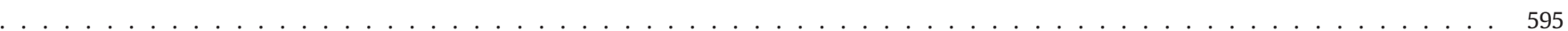

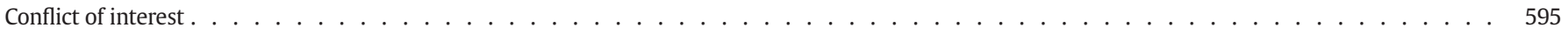

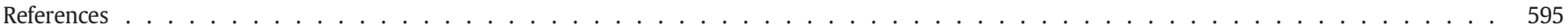

\section{Introduction}

Paper production processes often need to undergo modifications to meet the aims of cost reduction, improvement of product quality and compliance with environmental laws. Although electronic devices are increasingly being used for the display of information, the consumption of paper has remained high, even in European countries, partially due to the users' preferable choice over complex handling of digital media [1]. However, due to the lack of growth in the printing and writing $(\mathrm{P} \& \mathrm{~W})$ paper market, innovation is required to compensate for said stagnation with added value. This innovation will only be noticed by the customer if it involves developments in the surface appearance and/or printability of paper.

In papermaking, each process and component has its outcome impact on the surface properties, be it directly or indirectly. Smoothness, opacity, brightness and printability can be affected by several factors, such as fiber orientation, sizing treatment, filler and fine content, calendering nip pressure and coating [2]. Researchers from the Pulp and Paper Institute of Slovakia studied how sheet formation and coating composition (or formulation) influence print quality $[3,4]$. While the porosity and internal sizing degree of base paper ultimately affect the final smoothness and gloss of coated paper, only the coating formulation had a remarkable impact on print sharpness and water fastness.

Paper coating is a process in which a sheet with a uniform surface can be obtained by covering the cellulosic fibers of the outer boundaries and filling the space between them with binders (frequently, starch and/or synthetic latex), pigments and/or other agents [5]. This operation, generally followed by drying and calendering, is performed to obtain a paper with better sizing, printing and barrier properties [6,7]. A simplified representation of two common surface treatments in paper industries, size press coating and blade coating, is displayed in Fig. 1.

This review intends to highlight the general paper coating components and their effect on surface properties. Special emphasis is given to the promising applications of cationic starch and nanocellulose, two bio-based agents that have long been proposed as coating components $[8,9]$. However, the former's industrial use lies below expectations attending to its alleged advantages in literature, and the latter is far from being well established.

Most papermakers still refrain from producing nanocellulose and using it on-site mainly due to three reasons: dewatering difficulty, lack of conclusive research on continuous production (for scale-up) and the high energy input that is required [10]. It should be noted that most of the literature reporting the advantages of producing nanocellulose, does not consider the assumptions needed for industrial application [11,12]. Fortunately, recent advances involve an attempt to overcome these drawbacks. This review addresses and evaluates them, discussing whether or not they are powerful enough to cause a shift in paper mills.

Cationic starch is much better-known among paper manufacturers. It is often used in the wet end of the paper machine, both as a strengthening agent and as a retention aid. When applied onto the surface, it may be part of a sizing treatment, as described in the following pages. In all cases, and likely owing to costs of production, paper grade cationic starches seldom present a degree of substitution above $0.05[13,14]$. The usefulness of higher cationicities and some novel research showing interesting improvements on printability are explored.

Our motivation arises from the conflict between reported advantages and usage limitations of cationic starch and nanocellulose as paper coating agents. It is this conflict that creates opportunities for innovation, future research and greater added value. Our stand is that the benefits will be well worth the endeavor, that recent studies have set a proper path to overcome known challenges, and that further research along that path, as long as efforts from academics and papermakers are combined, will soon bear fruit.

\section{General components of paper coating formulation}

Different types of coating formulations are available and generally selected according to the expected product, namely P\&W paper, art paper, double or triple coated paper, one-sided coated paper, one- or two-sided cast coated paper, carbonless coated paper, thermal paper and metallized paper. In this review article, the coating components for the P\&W paper have been considered. They generally include pigment, binder, thickener, dispersant, crosslinker, optical brightening agent (OBA), lubricant and water. These components synergistically enhance the paper properties besides their individual functions [15].

However, other important properties for different papers will also be mentioned in the sections related to cationic starch (CS) and nanocellulose. A brief description of the most relevant components will be made in the following subsections.

\subsection{Pigment}

Coating solutions may contain different types of pigments such as grounded calcium carbonate (GCC), precipitated calcium carbonate (PCC), china clay, titanium dioxide, kaolin and plastic particles [16]. Calcium sulfate $[17,18]$ and egg calcium carbonate particles [19] have 
a)

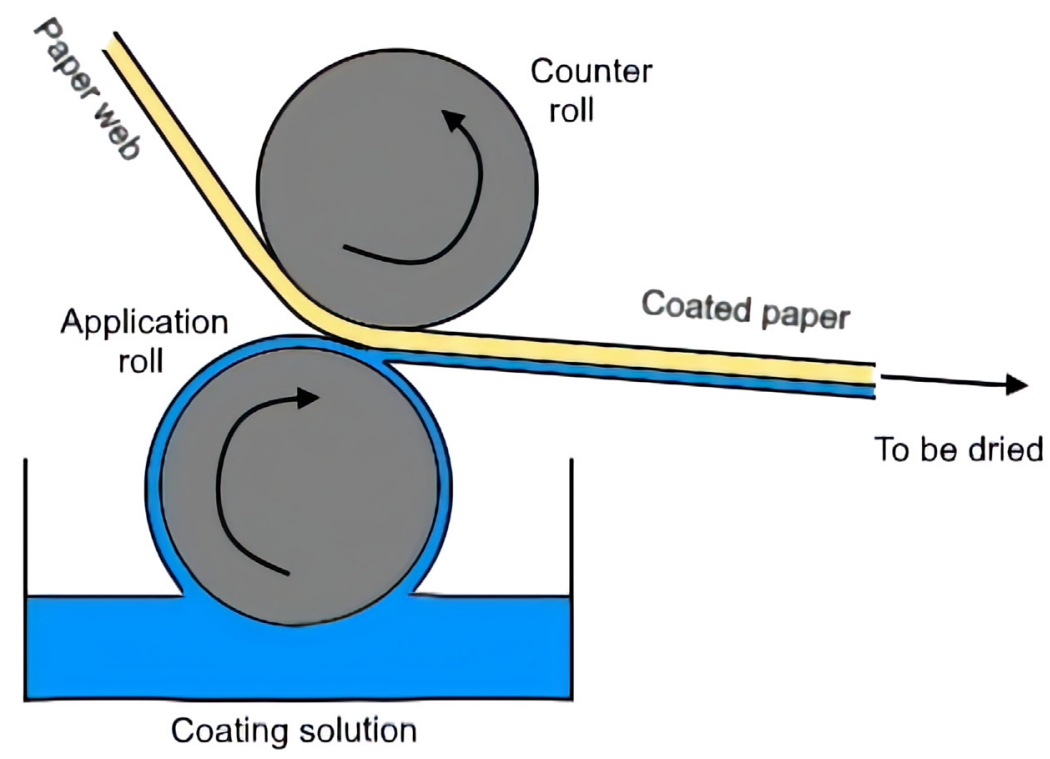

b)

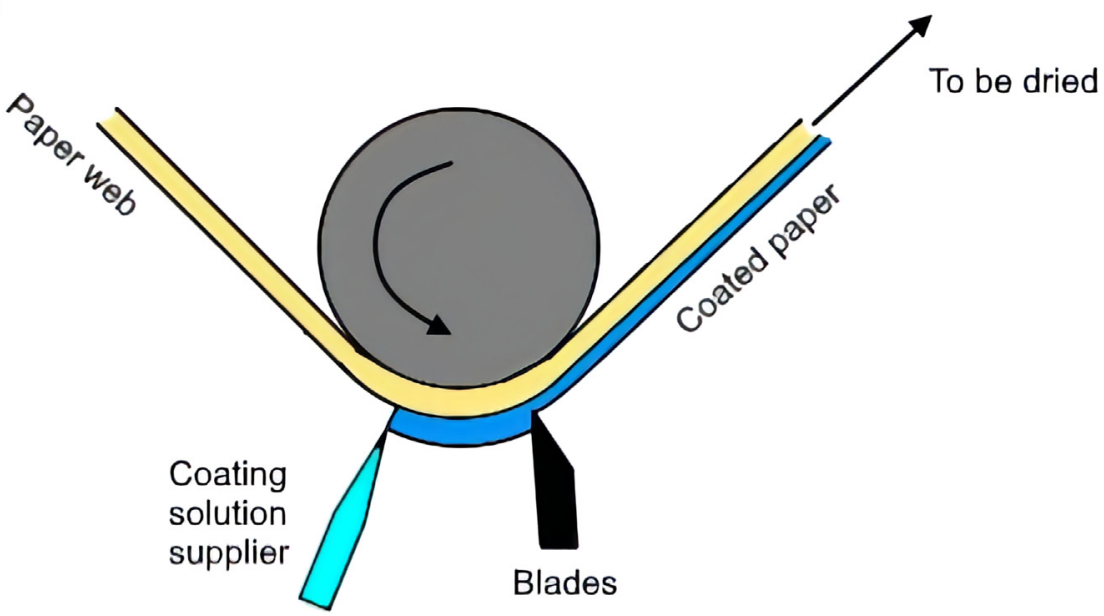

Fig. 1. Production of one-sided coated papers: a) size press coating; b) blade coating.

recently been identified as pigments that improve strength, optical and printing properties of coated paper. The surface properties are mainly affected by the shape, size and size distribution of the pigments [20], for instance, pigments with high aspect ratio show improved water absorptivity in comparison to blocky or spherical pigments [21]. However, it was also shown that spherical pigments have the best water vapor barrier properties owing to fewer cracks during folding operation [22].

Pigments generally support a structure of fine porosity and form a paper surface that scatters the light, resulting in improved paper brightness. The porosity and structure of coated paper also depend on the electrokinetic properties of the pigment colloidal system. Certain additives can be adsorbed on the pigment surface and modify the electric potential between the particles and the liquid, in order to achieve desirable structural properties of coating layers [23].

\subsection{Binder}

Pigments require binders in the coating formulation to attach them to the coating layers and fill the small pores between them. Usually, binders like glues, starches, styrene-butadiene latexes, styrene- acrylate latexes, poly(vinyl acetate) latexes, polyacrylates, gums, casein protein, soy protein and poly(vinyl alcohol) (PVA) are used to facilitate the coating operation [24]. Moreover, latexes prepared by graft copolymerization of a synthetic polymer and enzymatic cooked starch [25], hemicellulose-based gum extracted form distiller's dried grains [26], laccase modified lignosulfonate [27] and starch-based bio latex binder [28] have also been studied as binders in paper coating formulations.

The distribution of binders in the coating layer depends upon the size distribution and packing of the pigment particles [29]. In another study by Du et al. (2017) regarding the redistribution in terms of migration of starch-based bio-latex particles during coating drying, it was found that the binder migrates differently from the pigment and moves towards the surface of the coating layer. The topmost layer of the binder was found to be beneficial for producing bioactive papers by retaining enzymes at the surface [30,31].

\subsection{Thickener}

A thickener modifies the rheology of the coating solutions by adjusting the flow and leveling properties of dispersion. Thickeners 
are mainly required to obtain uniformity in the coating operation by varying the size distribution and morphology of the particles, resulting in an increase in the viscosity [32].

Different types of rheology modifiers are available, e.g., alkaliswellable dispersions and polymeric associative thickeners. However, alkali-swellable thickeners with high carboxylic group content reduce the viscosity at high shear rates, which is not required in the coating brushing process [33]. On the other hand, associative thickeners are water-soluble polymers containing hydrophobic groups, capable of interacting with the pigment-binder particles via a surfactant-like association [34]. Thickeners ease the bridging of a physical network for pigment and binder particles, which could be gradually destroyed in the shear field. The more stable this network is, the more intense shear forces are. Furthermore, interactions between associative thickeners and pigment binder particles can be controlled by the use of specific dispersing agents, based on hydrodynamic adjustments [35].

Hydrophobic ethoxylated urethane [32,33], organically modified bentonite [36], acrylic polymers, and cellulosic based water soluble thickeners such as carboxymethyl cellulose, hydroxyethyl cellulose, methyl cellulose, and hydroxypropyl cellulose are generally used in the paper coating formulations. Cellulose-based associative thickeners were hydrophobically modified using surfactant macromonomers and water-soluble surface-active monomers by graft copolymerization. Hydrophobically modified poly(ethylene oxide) (PEO) copolymers and hydrophobically modified polyacrylamides are also used as associative thickeners [34]. It is worth remarking that, over the past few years, there is little academic literature on fossil-based rheology modifiers. It seems that research efforts have recently shifted towards polysaccharides and, more particularly, as will be addressed later on, to nanocellulose [37,38].

\subsection{Dispersant}

Generally, coating formulations are highly concentrated solutions, and a well dispersed solid content is required to obtain a uniform coating layer on the paper surface. Dispersant molecules are commonly used to modify the surface potential of the particles. The electrostatic repulsions provided by the dispersant adsorbed onto the particles make them stable against the flocculation. The slight reduction in viscosity enables the highly concentrated coating colors to be used with great energy saving by easing the mixing process [39]. Ammonium polycarbonate [40] and polyacrylates [41] are examples of dispersants commonly used for stabilizing calcium carbonate suspensions. Polyphosphates and lignosulfonates silicates are also used in coating solutions. The selected dispersant may also enhance the mechanical properties of the paper if it strengthens the interaction at the pigment-binder interface [42]. Interestingly, nanocrystalline cellulose was also used as a dispersant to prepare a stable alkyl ketene dimer (AKD) emulsion [43].

\subsection{Crosslinker}

Crosslinkers insolubilize water-soluble binders and improve the paper offset printing properties by increasing the wet-pick resistance. Frequently, crosslinkers are aldehydes and their amino resins (melamine and urea), glyoxal resins, epoxy resins, imidazoline derivative and ammonium zirconium carbonate. Glyoxal is an efficient crosslinker for starch and its maximum working $\mathrm{pH}$ is 8.5. In contrast, melamineformaldehyde, urea-formaldehyde and their methylated forms work very efficiently at high $\mathrm{pH}$ although requiring long curing reaction times [44].

Since the presence of aldehydes raises environmental concerns, other procedures have been developed, such as speeding up curing and using alkaline components in the paper coating solution. Another alternative is the use of zirconium salts as effective crosslinkers; these salts can chelate with the hydroxyl groups or form covalent bonds with carboxyl group-containing binders to decrease the net surface energy, which increases the wet-pick resistance [45].

\subsection{Optical brightening agent (OBA)}

OBA improves the brightness of the paper substrate as it absorbs light in the ultraviolet region $(\sim 340-370 \mathrm{~nm})$ and re-emits the light in the blue region ( $420-470 \mathrm{~nm})$. It gives a fluorescent effect that reduces the yellowness of the paper fibers [46]. Most of the OBAs are bis (triazinylamino)stilbene derivatives, differing in the number of solubilizing sulfonic groups (e.g., di-, tetra- or hexasulfonated) in their structures. The sulfonic groups provide a specific affinity towards the paper substrate and improve the solubility in coating solutions [24]. The adsorption behavior of tetrasulfonate and hexasulfonate onto microfibrillated cellulose was recently studied by inverse gas chromatography [47]. Other OBAs such as coumarin [48], composites of 4,4'diaminostilbene-2,2'-disulfonic acid derivatives (PFB), PVA and layered double hydroxides [49] were found to be effective fluorescent brighteners that also improve the hydrophobicity of the paper.

\subsection{Lubricant}

Lubricants are generally used as anti-dusting agents at the calendering and printing process, improving the smoothness and gloss of paper. Calcium stearate dispersion is a widely used lubricant in paper industries. In order to prevent dusting through supercalendering processes and modern high-speed cast coaters, it is required to optimize the release properties, the adhesion behavior and the thermal stability of the lubricants [50].

\section{Potential of polysaccharides for paper coating}

Generally, paper is regarded as a biodegradable and recyclable material. Cellulose fibers are biodegradable themselves, and some of the products added through papermaking processes may include other polysaccharides such as starches, alginates and/or carboxymethyl cellulose. As for the mineral fillers added to the furnish, they are mostly innocuous (excluding cases of massive deposition) and naturally found in many ecosystems. However, the polyethylene layers applied in plastic-coating processes are non-biodegradable, contribute to debris pollution and usually prevent paper from being recycled. Wax coating also hinders recycling, although it gives out better degradability. Even synthetic latex binders, widely used for coating, result in nonbiodegradable contaminants in paper sludge and tacky deposits (stickies) during recycling [51]. Petro-based retention aids or strength agents, e.g., polyacrylamides and polyethylenimine, are poorly biodegradable [52].

Most of the recent research on coating solutions is conducted towards truly biodegradable paper. Poly-3-hydroxybutyrate, poly(lactic acid), casein, beeswax, chitosan with palmitic acid, and poly(3hydroxybutyrate-co-3-hydroxyvalerate), for instance, have been proposed as green alternatives to conventional plastics $[48,49,53]$. These materials, nonetheless, are less economically feasible than their petrobased counterparts. Cheap polysaccharides like native starch and cellulose, on the other hand, do not grant good water barrier properties. This problem can be tackled by hydrophobizing them with AKD or octyl moieties, to name some possibilities [50,51]. Song and Rojas [56] have extensively reviewed the diverse ways to impart super-hydrophobicity on a cellulosic surface.

In any case, even when chemical modifications are needed, the complete replacement of petro-based coating components by readily biodegradable polysaccharides is technologically feasible. Among them, the following sections deal particularly with cationic starch and nanoscale cellulose, due to their versatility and to the potential development of their syntheticroutes. Their possible applications cover practically all functions of coating layers, plus strengthening when added before 
sheet formation. Finally, their drawbacks give all the more reason to keep exploring how to overcome all pending challenges.

\section{Cationic starch (CS)}

Starch is a natural, biodegradable, highly available, renewable and relatively cheap material. European production of this carbohydrate accounted for nearly 10.7 million tonnes in 2018 [57]. It is actually a mixture of two different polysaccharides, namely amylose and amylopectin, where amylose is a linear polymer consisting of 1-4 linked $\alpha$-D-glucopyranose units. Amylopectin is a highly branched polymer, constituted by 1-4 linked and 1-6 linked $\alpha$-D-glucopyranose units, and its proportion in natural starches may be as high as 95\% [58]. At a supramolecular level, these polysaccharides are found to form grains that can be up to $100 \mu \mathrm{m}$ in diameter, as shown in Fig. 2. From the nucleus, known as hilum, the grain grows outwards as amylose is successively branched. Branches take place particularly in the less crystalline lamellae, which different authors identify as "amorphous" or "semicrystalline" [54,55].

The gelatinization properties, retrogradation ability and crystallinity of starch are highly appreciated in papermaking. However, some of its features are unfavourable in certain cases, such as being insoluble in most solvents at room temperature and unstable to changes in $\mathrm{pH}$, temperature and shear forces [59]. Therefore, chemical modifications of starch, including etherification with cationic functional groups, are often advantageous. Cationic starch ethers are used extensively in paper manufacturing, wastewater treatment and medicine, to name a few of their many applications known today [60].

\subsection{Synthesis of CS}

There are several well-known methods allowing the cationization of starch raw materials. In general, CS is obtained by attaching positively charged groups to the carbohydrate backbone. Examples of those are iminium, ammonium, sulfonium and phosphonium groups [60].

\subsubsection{From dry to wet methods}

Starch can be functionalized by different methods such as extrusion, semidry and wet processes. In the extrusion process, the reagents are added to dry native starch in the presence of a plasticizer, e.g. glycerol [61]. In the semidry process, the reagents are required to be sprayed uniformly over the dry native starch and the mixture is finally exposed to a thermal treatment [62]. During the wet process, the reagents are added either in homogeneous or heterogeneous media to starch, depending on the solvent. Dissolution of starch can be achieved, most commonly, in dimethyl sulfoxide (DMSO) or dimethylformamide (DMF) $[63,64]$. On the other hand, heterogeneous conditions for the wet process can be ensured by using an aqueous-alcoholic mixture including ethanol, methanol or isopropanol $[65,66]$.

Regardless of the method, the native starch structure is degraded by cationization. However, the molar mass distribution is particularly affected by the extrusion process, while the wet method has the least effect. This is possibly due to crosslinking of CS with the by-products formed during extrusion, as indicated by observing lower solubility and increased viscosity with increasing degree of substitution (DS) [67].

Hellwig et al. [65] studied the benefits of dry and semidry methods over wet processes, concluding that the former shows less reaction time, low energy input and less effluent pollution. The dry method is also favored for paper coating because it produces denser CS, which results in higher retention [68]. More recently, ball milling has arisen as a new possibility to use the dry method for obtaining CS with traditional cationizing reagents [69]. This way, researchers reached a DS of 0.30 , which is, as far as we know, much higher than any commercial cationic starch for papermaking.

However, since the advantages of dry and semidry methods are mainly due to the lack of washing or filtration steps, impurities like

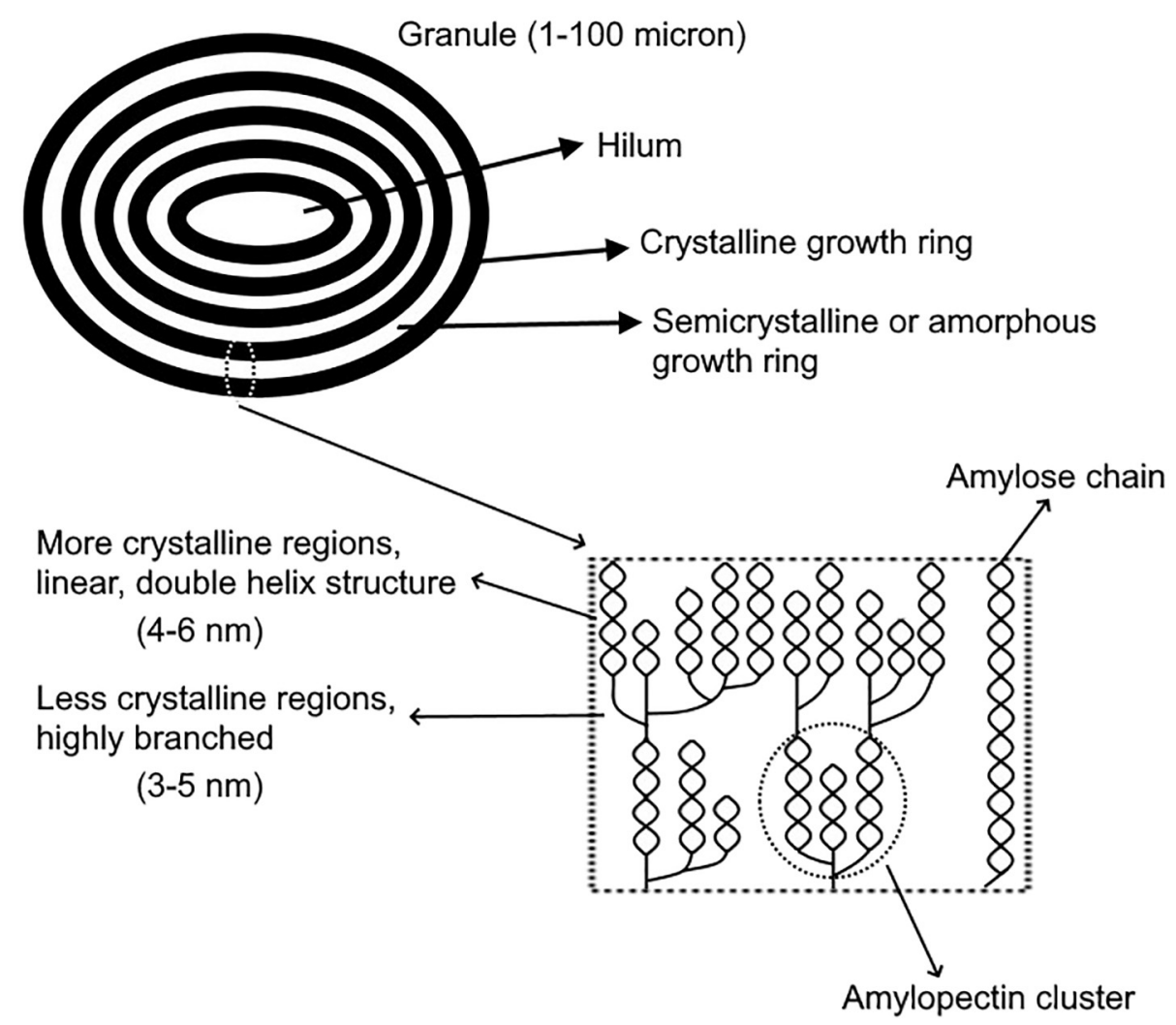

Fig. 2. Granular structure of natural starches. 
residual salts, reagents or by-products remain in the material supplied to the papermaker, raising some concerns [67]. Nowadays, these problems of harmful by-products are addressed by giving a boost to wet methods for the synthesis of CS and its applications in several fields.

Wet processes in homogeneous media are reported to achieve the highest degrees of substitution, owing to carbohydrate chains being more accessible to reagents. On the other hand, undissolved starch shows hydrophobic interactions hindering the diffusion of cationizing agents through the granules [70]. Nevertheless, some of the CS applications have been found suitable for the heterogeneous conditions, such as flocculation, for which the granular structure of starch is desired to be preserved $[71,72]$.

\subsubsection{Cationizing agents}

Nowadays, two commercially relevant reagents, 3-chloro-2-hydroxypropyl trimethyl ammonium chloride (CHPTAC) and 2,3-epoxypropyl trimethyl ammonium chloride (EPTAC), are in use to produce CS under alkaline medium (mostly using $\mathrm{NaOH}$ ). In the presence of CHPTAC, the cationization process occurs in several steps: formation of an epoxy group (CHPTAC to EPTAC), simultaneous activation of the anhydroglucose units (AGU) by forming alkoxide and, finally, nucleophilic substitution to introduce the 2-hydroxypropyltrimethylammonium group in the starch chains [73], as shown in Scheme 1. Moreover, kinetics of the cationization reaction can be improved by using excess alkali in both the homogeneous and heterogeneous conditions [74].

EPTAC can also be used directly in this reaction. However, it is beneficial to use the chlorohydrin instead of the epoxide because the latter degrades at ca. $3.5 \%$ a month at $20{ }^{\circ} \mathrm{C}$ during its storage and has a demanding temperature range $\left(2-8{ }^{\circ} \mathrm{C}\right)$ for storing [75].

Over the years, starch etherification with CHPTAC has proven its versatility and robustness. Nevertheless, the reaction has some drawbacks worth mentioning, like the formation of diol and other toxic byproducts. Additionally, consecutive steps like dispersing the starch, reaction with the reagents in alkaline medium, neutralization of reaction mixture, separation, washing and drying of the final product are commonly required [76].

Some alternatives to etherification for the production of cationic starch have arisen. For instance, esterification with betaine hydrochloride has been reported in the presence of different reagents such as diisopropylcarbodiimide and 4-dimethylaminopyridine [77], thionyl chloride [78], and carbonyldiimidazole [63]. This way, a more easily biodegradable CS is obtained. Examples can be observed in Scheme 2, corresponding to Steglich esterification, and Scheme 3, which involves the previous conversion of betaine hydrochloride to $\mathrm{N}$-chlorobetainyl chloride [78].

Other works involve the previous oxidation of the anhydroglucose units to the dialdehyde form, e.g. with sodium periodate. At least one of the carbonyl groups is prone to react with a hydrazine which may contain a cationic functional group, as exemplified in Scheme 4. The synthesis of cationic dialdehyde starches was published for the first time in the sixties, with the aim of wet strengthening of paper [79]. While the oxidation of starch is still used as an intermediate step for a wide range of derivatives, cationic dialdehyde starches were somehow disregarded in favor of less toxic processes.

\subsubsection{Factors governing cationization}

Reaction parameters such as reagent to AGU ratio, reaction time, temperature, $\mathrm{pH}$, raw material and type of solvent are involved in the synthesis of the CS with different DS. The main reaction conditions and reagents used in several papers are summarized in Table 1.

The DS of the final product is generally higher with increasing reagent to AGU ratio [80] and, at least for etherifications, increasing alkali charge [81]. Nonetheless, Kavaliauskaite et al. [81] also noted that an excess of $\mathrm{NaOH}$ may favor the degradation of starch and the formation of unwanted by-products such as diol and 3-hydroxy-1-propen-1trimethylammonium chloride (see Scheme 5). It is out of the question to replace $\mathrm{NaOH}$ with organic bases like triethylamine and dimethylbenzylamine, as they have been shown to drastically slow down the reaction rate [82]. The DS and the final molecular weight (MW) depend strongly on $\mathrm{pH}$ and temperature ( $\mathrm{T}$ ), as the stability of EPTAC is very sensitive to both of them. The suitable range for $\mathrm{T}$ and $\mathrm{pH}$ are 20 to $50{ }^{\circ} \mathrm{C}$ and 10.5 to 12.5 , respectively, independently of the solvent. The source of starch (potato, maize, waxy maize, etc.), varying largely in their amylose content and average MW, has a slight influence on the DS [81].

Regarding the solvent, queous media may be the only economically feasible way to produce paper grade CS, but it is worth taking a look at solvents that completely disrupt the crystalline structure of starch and solubilize it. This is the case of ionic liquids like 1-butyl-3methylimidazolium chloride (BMIMC), in which etherification can reach DS values up to 0.99 [83]. An even higher DS, as high as 1.5 , was attained by Heinze et al. [64], who used two consecutive steps of etherification in dimethyl sulfoxide (DMSO) [64]. As can be seen from Table 1, the approaches resulting in the highest DS involve the choice of an aprotic solvent or a mixture of water and an aprotic solvent as the reaction medium.

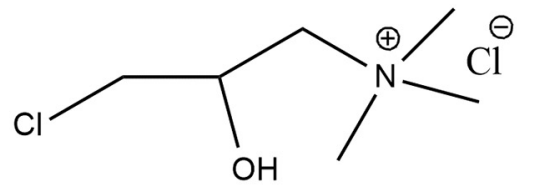

CHPTAC

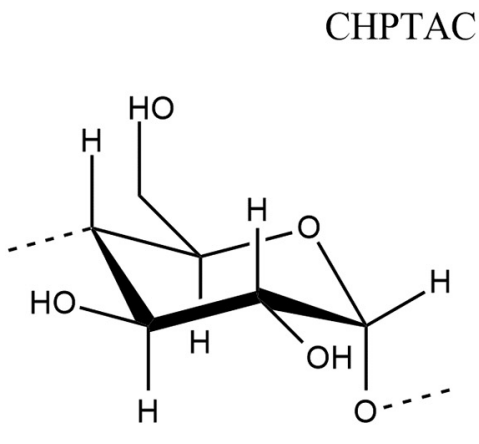

AGU

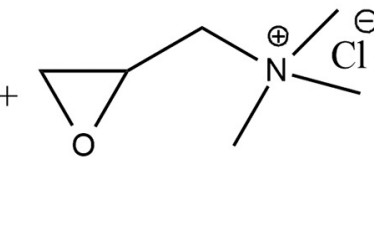

EPTAC
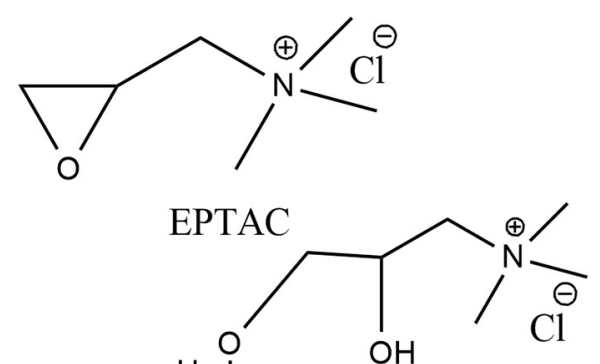

Scheme 1. Etherification: production of CS from native starch by reacting with CHPTAC in alkaline aqueous medium. 
<smiles>C[N+](C)(Cl)CC(=O)O</smiles>

Betaine hydrochloride
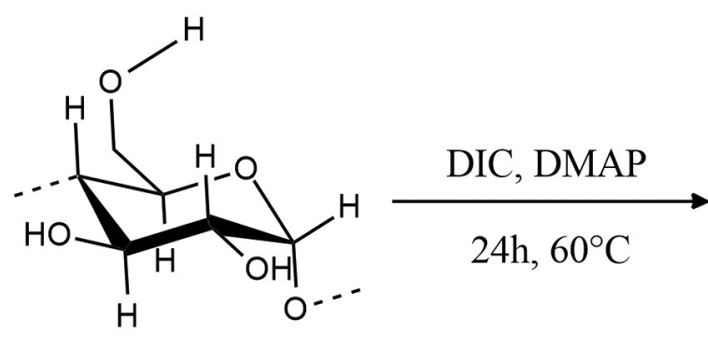

Scheme 2. Esterification of starch in presence of betaine hydrochloride, diisopropylcarbodiimide, and 4-dimethylaminopyridine [77].

N-chlorobetainylchloride

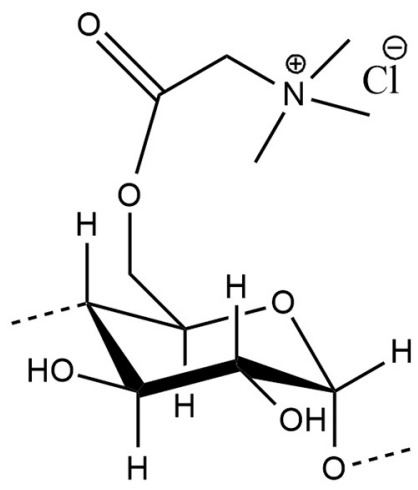

Starch betainate chloride<smiles>C[N+](C)(Cl)CC(=O)O[Cl+]</smiles>

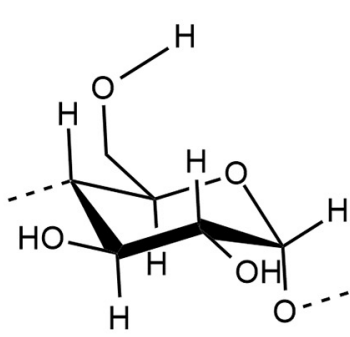

AGU

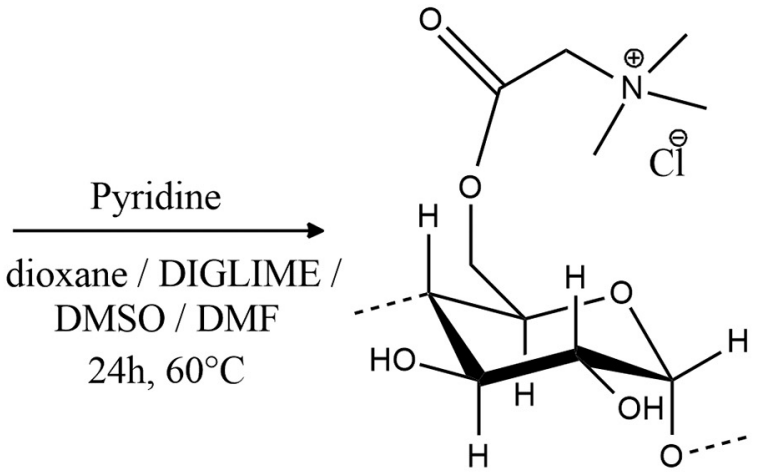

Starch betainate chloride

Scheme 3. Esterification of starch in presence of $\mathrm{N}$-chlorobetainyl chloride and pyridine.<smiles>CC(C=O)C(CO)OC([OH2+])OC=O</smiles>

Dialdehyde starch<smiles>C[N+](C)(C)CC(=O)NN</smiles>

Betaine hydrazine hydrochloride

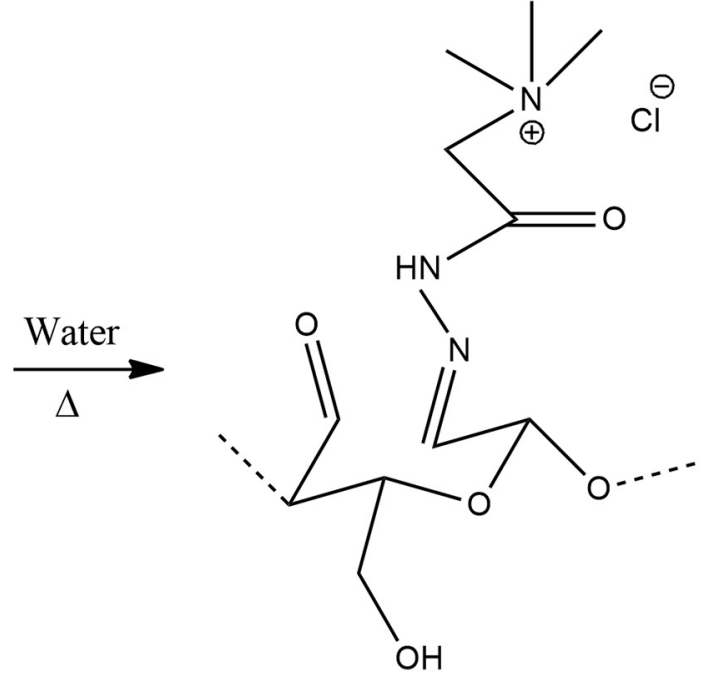

Cationic dialdehyde starch

Scheme 4. Monosubstitution on dialdehyde starch with a cationic hydrazine to synthetize the corresponding hydrazine.

\subsubsection{Analysis of CS}

Techniques like infrared (IR) spectroscopy, elemental analysis, NMR, viscosity measurements, potentiometric titrations and thermogravimetric analysis can be used to optimize the process and standardize the cationized polysaccharides for their potential uses [13,84]. E.g., the absorption band at $1480 \mathrm{~cm}^{-1}$, assigned to the $-\mathrm{N}^{+} \mathrm{Me}_{3}$ groups, is linearly correlated with the DS, which proves the usefulness of IR spectroscopy (non-destructive, timesaving, not requiring sample preparation) 
Table 1

List of reagents, conditions and main results found in the literature for the synthesis of cationic starches.

\begin{tabular}{|c|c|c|c|c|c|}
\hline Reagents & $T\left({ }^{\circ} \mathrm{C}\right)$ & RT (h) & DS (range) & Remarks & Reference \\
\hline CPTMAC, CDI & 70 & 20 & Up to 0.73 & DMSO as solvent. Antimicrobial agent & [63] \\
\hline EPTAC & 60 & 6 & Up to 1.5 & DMSO as solvent, two-step reaction & [64] \\
\hline CHPTAC & 50 & 18 & $0.4-0.75$ & Flocculation agent for silica & [72] \\
\hline CHPTAC & 60 & 6 & $0.36-1.07$ & Flocculation agent for harbor sediments & [73] \\
\hline CHPTAC & 70 & 2 & Up to 0.24 & Sizing and flocculation agent in papermaking & [76] \\
\hline Betaine hydrochloride, DIC, DMAP & 25 & 24 & $0.25-0.3$ & DMSO as solvent, inert atmosphere & [77] \\
\hline $\mathrm{N}$-chlorobetainyl chloride, pyridine & 110 & 4 & 0.2 & 1,4-Dioxane as medium & [78] \\
\hline CHPTAC & 65 & 4 & Up to 0.7 & Strength agent for papermaking & [80] \\
\hline EPTAC & $45-75$ & $24-72$ & $0.2-0.85$ & Study of the effects of temperature, time and concentration on DS & [81] \\
\hline EPTAC & 45 & $24-48$ & $0.18-1.05$ & Organic bases (such as triethylamine) & [82] \\
\hline EPTAC & 80 & 2 & Up to 0.99 & An ionic liquid (BMIMCl) as solvent & [83] \\
\hline EPTAC & 80 & 2 & Up to 0.037 & Strength agent for papermaking & [88] \\
\hline
\end{tabular}

CPTMAC: 3-chloropropyl trimethyl ammonium chloride. CDI: 1,1'-Carbonyldiimidazole. DIC: N,N'-Diisopropylcarbodiimide. DMAP: 4-Dimethylaminopyridine.

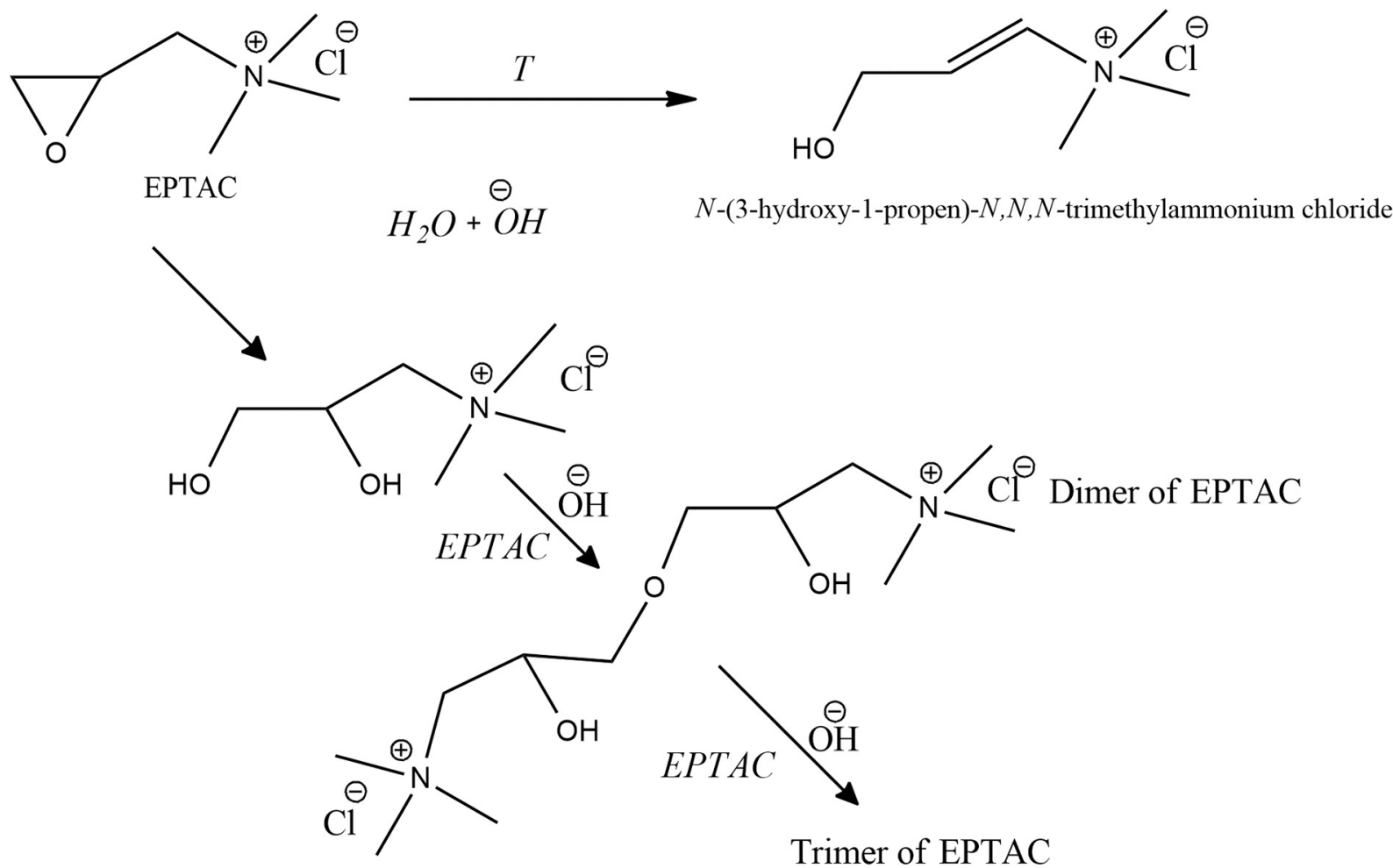

Scheme 5. Side reactions of EPTAC [81].

[84]. Trimethyl ammonium groups can also be quantified by analytical pyrolysis-gas chromatography-mass spectrometry for the measurement of CS in paper substrates [85]. For detailed insights into analytical techniques, the recent review of Chemelli et al. [13] is recommended.

The use of CS in the fields of medicine, papermaking and wastewater treatment has encouraged the use of use environment-friendly reagents and process conditions for their production. Hence, in the future, green process conditions are required to be identified for the cationization of starch, along with their potential applications.

\subsection{Applications of CS in papermaking}

CS with a low degree of substitution has a great affinity towards cellulose materials by irreversible deposition on their surfaces [86]. However, other polycations in the coating formulation such as polyvinylamine, polyethylenimine, polyacrylamide and poly(diallyldimethylammonium chloride) (PDADMAC) behave as competitors for the attachment on the paper surface, which reduces the CS sorption on the paper. It was suggested that the CS can be added before the other polycations to minimize this competition. Once adsorbed, CS with low DS is difficult to replace by synthetic polycations [87].

\subsubsection{Wet end chemistry}

Over time, CS has been used extensively for improving the paper dry strength when added to the pulp slurry $[80,88]$. This application is well established in the paper industry and most of the recent innovation comes from synergy with other materials. CS with nanoclay montmorillonite (MMT) and ZnO nanopowder has been shown to enhance the mechanical and optical properties for food packaging and drug delivery system [89]. Chitosan may also be used with the CS to increase the dry strength of non-wood papers [90]. This strengthening is related to the ability of CS for binding fibers and/or fillers together. In other words, it is related to flocculation.

Liu et al. [91] reported higher retention of small cellulosic fibers in papermaking with the use of highly substituted cationic starch (HCS), with a DS of roughly 0.64 . However, large doses are required to promote 
flocculation to a noticeable extent [92]. Similarly, Zhang et al. [93] also found that highly substituted starch betainate (DS 0.32) improves the flocculation of a kaolin suspension, achieving a removal ratio of turbidity as high as $90 \%$.

Pal et al. (2005) also studied the use of HCS for wastewater treatment, showing that a higher charge density results in higher energy dissipation rate, lower collision efficiency, lower restructure rate and stronger flocs in the flocculation system [72,94]. Due to these properties of CS, it can also be utilized in the paper recycling process to remove the tacky contamination from the recycled pulp, aiming at quantifying the sticky particle content in the wastewater [95]. In fact, this idea is closely related to a patent granted to Ecolab USA, Inc. [96]. The document reports that, by using $25 \mathrm{ppm}$ of a suspension of cationic starch and hydroxypropyl cellulose, detackification percentages of up to $95.1 \%$ were obtained. As another possibility for recycling, starch grafted with acrylamide and dimethyl diallyl ammonium chloride was identified as an effective flocculating agent for the removal of dyes from water [97].

HCS with DS up to 1 was also used in the presence of a polyanion in a binary polyelectrolyte flocculation system [73]. Alternatively, amphoteric starch can be produced by inserting anionic functional groups into CS, or simply by cationizing the naturally anionic potato starch, to improve the aggregation of kaolin $[98,99]$. However, the interactions between the CS and anionic surfactants diminished the flocculation efficiency due to the formation of polymer-surfactant complexes [100].

Along these years, combinations of CS with different polymers and particles were tried, in order to increase the flocculation efficiency, e.g., blending with chitosan [101]. The incorporation of CS into a polyacrylamide system was found to improve the flocculation of $\mathrm{CaCO}_{3}$ particles, ubiquitous in paper mills [99]. On the other hand, flocculation efficiency of cellulosic fibers was found to decrease in the presence of higher ionic strength [92].

\subsubsection{Sizing}

Sizing is a surface treatment which improves the hydrophobicity of the paper substrate. Rosin size, wax and aliphatic materials, low MW starch, alkyl ketene dimer (AKD) and alkenyl succinic anhydride (ASA) are some typical sizing chemicals which have been used over time. These chemicals were developed according to evaluations of their performance in papermaking, their compatibility with other size components, and with the aim of reducing the final cost of finished paper.

Recently, it has been shown that some polysaccharide derivatives, such as carboxymethylated cassava residue (starch and cellulose), can be used as sizing agents [102]. Indirectly, CS is also used to improve sizing by increasing the stability of sizing reagents such as AKD and ASA. CS increases the strength of the interface film in the AKD or ASA emulsion for its long storage and easy transportation [103]. At the moment, this application, generally involving lowly substituted CS (DS lower than 0.05 ), is the only conventional use of this derivative in industrial surface treatments. Interestingly, HCS with a DS of 0.15 can be used as an internal and external paper sizing agent alone [104]. In any case, the usefulness of CS for sizing is long known and, unfortunately, no breathtaking innovation has taken place in the past few years. Some authors have even stated that CS is not an efficient stabilizer, claiming that either a large amount of the cationic polysaccharide or the addition of a co-emulsifier is required $[14,105]$. Such a statement may be true for currently available cationic starches in the market, but this review encourages testing alternatives involving higher DS and/or different functional groups.

\subsubsection{Printing quality}

Paper intended for inkjet printing has generally undergone coating. Without surface treatment, paper shows a greater tendency to absorb water, resulting in poor printing properties while printing with dye or pigment-based ink. Also, the dye or pigment carrier solution penetrates through the paper surface quickly. The leftovers migrate on the surface during printing, resulting in printing flaws such as high inter-color bleed. Therefore, an adequate amount of hydrophobicity for improving the ink-carrier adsorption, along with better ink fixing properties, is required [106,107].

Modified starches were also found suitable for usage at the surface of paper to improve optical and printing properties. Moreover, with the use of HCS (DS 0.1 to 0.3 ) in size press, paper properties like opacity, brightness, print gloss, ink density and picking resistance improve due to their better holdout ink compared to oxidized starch [108]. In addition to improved printing properties, the whitewater from the paper treated with HCS showed better quality parameters, including a reduction of the chemical oxygen demand (COD).

About 4\% of HCS (DS being at least 0.125 ) in the coating solution confers satisfactory optical density and whiteness to the paper surface, being said to surpass PDADMAC in some respects [91]. However, the differences reported are not significant: whiteness goes from $86.6 \%$ with PDADMAC to $86.9 \%$ with HCS, and color density is extremely similar as well. At least, it is undoubtedly valuable that a bio-based agent can successfully replace one that ultimately comes from propylene. Likewise, Gigac et al. [4] also coated paper with HCS and other highly cationic polymers (PDADMAC and a maleic anhydride copolymer) and reported much higher print sharpness and water fastness. Sharpness went from $35.3 \%$ with PDADMAC, which showed better performance than the copolymer, to $79.2 \%$ with HCS. Fastness went from $77 \%$ with PDADMAC to $94 \%$ with HCS [4]. Still, in those formulations, the concentration of HCS was $30 \%$, whereas that of PDADMAC was $2.5 \%$ and that of maleic anhydride copolymer was $2 \%(w / w)$. As impressive as those numbers are, it is unlikely that paper manufacturers will want to spend that much HCS per unit of paper.

Cationic sizing reduces ink feathering due to the electrostatic adsorption of anionic dyes, resulting in quick fixation of ink particles onto the paper surface and preventing their migration. The use of cationic additives on the paper surface also reduces the coating permeability, which further slows down the ink penetration into the paper structure and improves water fastness in the printing operation [109]. Moreover, the papermaking cost can also be reduced by using these cationic binders, as they allow for the use of the low-cost mechanical pulp along with the adequate amount of fillers [110].

Another polyhydroxy-based binder, PVA, along with other coating components such as anionically dispersed pigments, have also been included in the coating formulation for improving ink adsorption. PVA, which can be used as-is or cationized with quaternary ammonium groups, facilitates the interpolymer diffusion of the ink carrier [109], most probably due to its amphiphilic behavior [111,112]. Sousa et al. [9] compared a paper grade CS and PVA for the improvement of the inkjet print quality and concluded that PVA shows more improvement in the printing properties, particularly the gamut area (roughly, 8400 for PVA and 7500 for CS). A representation of the gamut area can be referred to in Fig. 3. The higher hydrophobicity and smoothness of PVAtreated surface were suggested to be the possible reasons for the higher gamut area when compared to the surface coated with CS. An equally valuable comparison between PVA and CS with different conclusions came years later, when Gigac et al. [113] obtained better optical density for black ink with the cationic polysaccharide (2.06 compared to 1.92), and found the color gamut area to be only slightly lower. However, once again, the concentration of CS was much higher (15.2\%) than that of PVA (3.5-4\%). This was understandable, as the viscosity should be within a certain range for proper surface treatments. An adequate CS for printing enhancement should differ from current paper grade CS not only in the DS, but also in the intrinsic viscosity.

A coating formulation without any pigments was developed and reported to increase printability in a similar way to pigment-containing formulations. The major components for this formulation were aluminum sulfate and styrene-acrylic copolymer along with cationic PVA or CS. This invention provided the inkjet papers with enough water resistance, barcode printability, abrasion resistance, and uniform printed area [114]. 


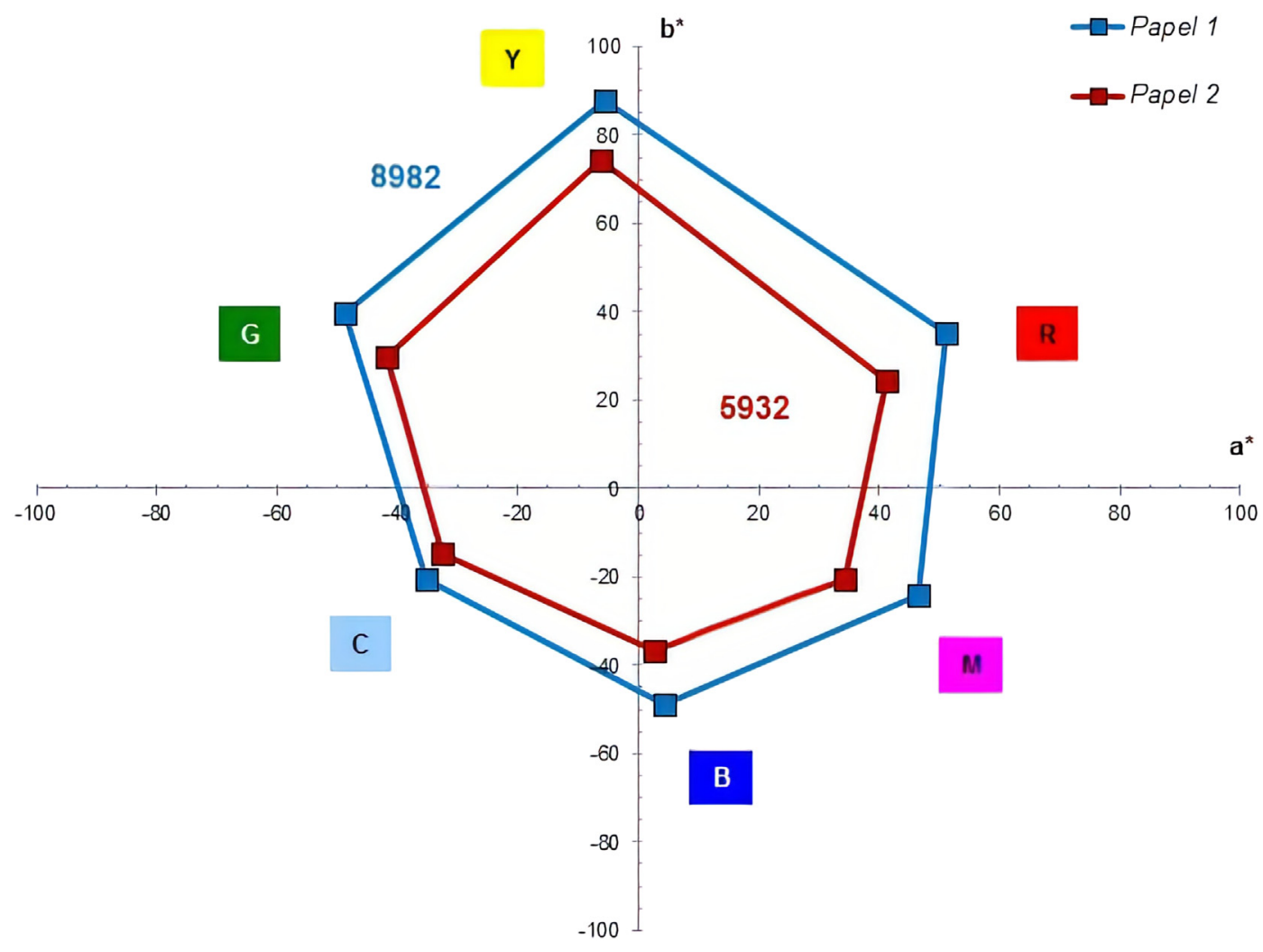

Fig. 3. Representation of Gamut areas (Paper 1 shows higher Gamut area than Paper 2).

\section{Nanocellulose}

Nanocelluloses, which can be defined as nanoscale building blocks derived from cellulose, have attracted widespread attention in different research areas, due to characteristics such as high mechanical strength, high specific area, modifiable physical \& chemical properties, good biocompatibility, biodegradability, adjustable surface chemistry and transparency [115-117]. However, to utilize nanocellulose at an industrial scale, its production should be economical and, if possible, continuous.

Cellulose is a linear homo-polysaccharide, constituted by $\beta-D-$ glucopyranose units. Two molecules of D-glucopyranose monomers linked by a $\beta-1,4$ glycosidic bond can be represented as a cellobiose unit (length $\sim 1 \mathrm{~nm}$ ), as shown in Fig. 4. Cellulose chains, besides being constituted by the repetition of cellobiose, have hydrogen bonds (H-bonds) within a chain and between chains to form the elementary fibrils (diameter of 3-4 nm), and to further form the microfibrils (approximately $12 \mathrm{~nm}$ diameter) that constitute a fiber [118]. Fig. 5 displays a cellulose fiber splitting into its fibrils.

\subsection{Classification of nanocelluloses}

Nanocelluloses can be classified, depending on their production process and on final dimensions, as cellulose nanofibrils (CNFs), cellulose microfibrils (CMFs), cellulose nanocrystals (CNCs), amorphous nanocelluloses (ANC), bacterial nanocelluloses (BC), and cellulose nanoyarn or electrospun nanofibers $[119,120]$.

\subsubsection{Cellulose nanofibrils (CNFs) and cellulose microfibrils (CMFs)}

CNFs can also be called nanofibrillar cellulose or cellulose nanofibers, whereas CMFs can also be named microfibrillar cellulose or cellulose microfibers. Both CNFs and CMFs encompass amorphous and crystalline regions of cellulose with a high aspect ratio. These fibers are usually above $1 \mu \mathrm{m}$ in length (up to several micrometers) and, in the case of CNFs, the width lies between 1 and $100 \mathrm{~nm}$. Microfibrillar cellulose is more difficult to define since it often comprises nanofibers, fibrillar fines, fiber fragments and small fibers.

CNFs are very flexible and long enough to become entangled in a bundle of stretched cellulose chains. Therefore, these nanoscale fibers are good for strengthening, reinforcement, and rheology modification in paper mills [121-123].

\subsubsection{Cellulose nanocrystals (CNCS)}

CNCs, also known as nano-whiskers or nanorods, can be produced by isolating the crystalline region of cellulose. These nanocrystals have an elongated shape with low flexibility and usually diameters of 2-20 $\mathrm{nm}$. CNCs have lengths as short as $100 \mathrm{~nm}$, which gives them a smaller aspect ratio than that of CNFs $[123,124]$. The degree of crystallinity and the morphology of CNCs highly depend on the raw cellulosic materials, preparation conditions and techniques. These nanoscale crystals can be functionalized to reduce hydrophilicity, impart negative or positive charge and achieve acidic or alkaline behavior, among other purposes. They are useful not only for strengthening, reinforcement and rheology modification, but also to enhance optical, electrical, and chemical properties [125].

\subsubsection{Amorphous nanocellulose (ANC)}

ANC with an average diameter of $50-200 \mathrm{~nm}$ can be obtained by acid hydrolysis of regenerated cellulose followed by ultrasound. Unlike CNFs and CNCs, amorphous nanocellulose shows poor mechanical strength due to its lack of a crystalline structure. Generally, ANC can be used as a thickening agent and carrier of bioactive substances due to its high functionality. Since hydroxyl groups are less hindered, ANC is normally better for both absorption and adsorption than crystalline cellulosic materials [126]. 


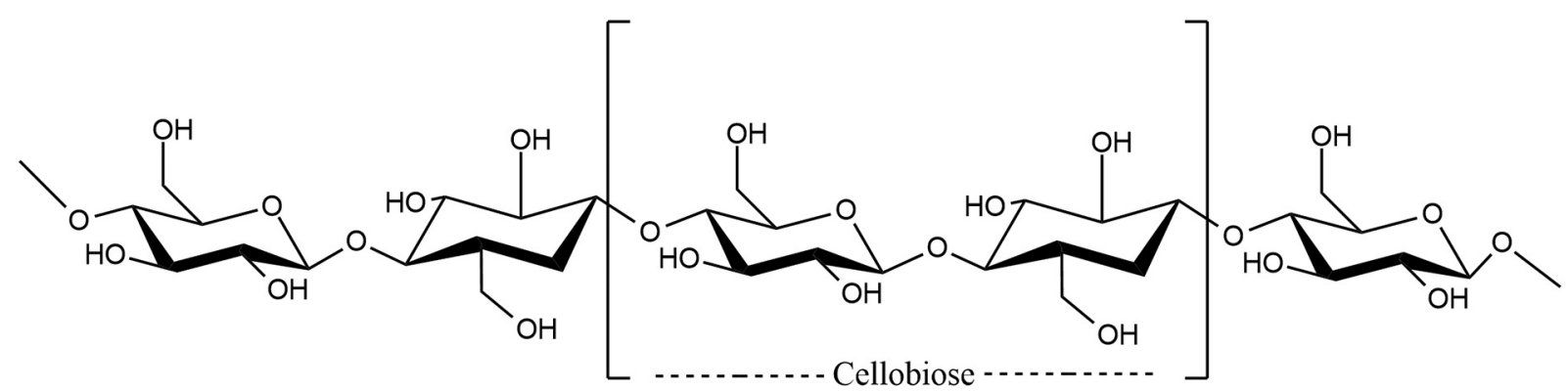

Fig. 4. Molecular structure of cellulose.

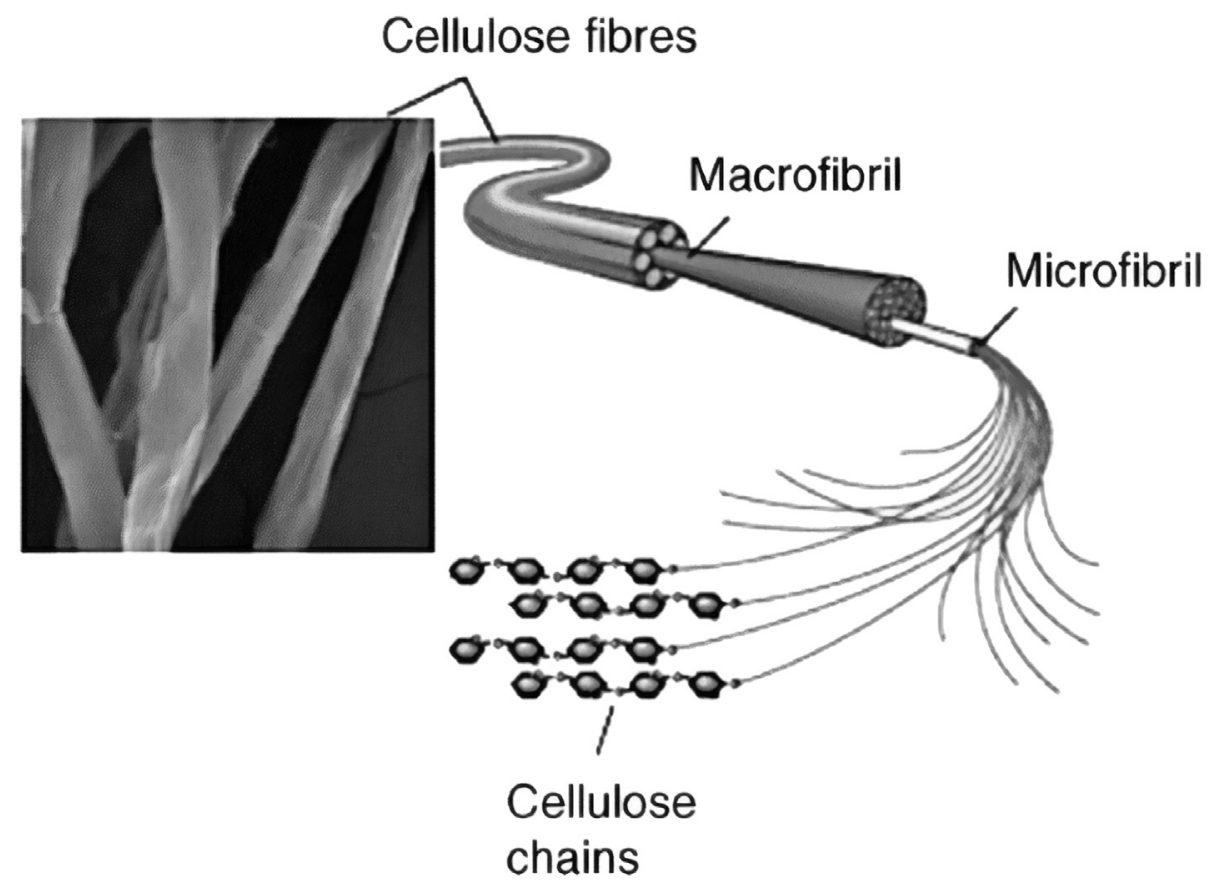

Fig. 5. Cellulose as found in nature: from fibers to microfibrils.

\subsubsection{Bacterial cellulose $(B C)$}

$\mathrm{BC}$ is also known as biocellulose or microbial cellulose. It is generally produced by a bottom-up method unlike the aforementioned micro- or nanocelluloses, which are produced via top-down methods. BC possesses high MW, crystallinity and good mechanical endurance [123,127]. 20-100 nm long microbial cellulose fibers are produced by bacteria such as Gluconacetobacter or Acetobacter xylinum through polymerization of glucose. The resulting chains aggregate as ribbons, giving shape to the distinct tunnel, porous structure of BC [128].

\subsubsection{Cellulose nanoyarn (CNY) or electrospun nanofibers}

CNY or electrospun nanofibers can be obtained by electrospinning of dissolved cellulose. Generally, these types of nanofibers are 500 to 800 $\mathrm{nm}$ in diameter, with low crystallinity and thermal stability compared to other nanocelluloses. In any case, the commercialization of bacterial cellulose and cellulose nanoyarn remains under question because of their lower production rate [126].

\subsection{Production of nanocellulose}

The crystallinity, mechanical strength and surface chemistry of nanocellulose greatly depend on the processing techniques used to obtain it. Nanocelluloses like CNFs, CNCs, and ANC can be generated by mechanical disintegration, although this technology requires high energy input. Fortunately, pretreatments like enzyme hydrolysis and TEMPO oxidation have been developed over the past few years to overcome the need for high energy demand [123]. These production methods and pretreatment technologies can be found in Fig. 6 .

\subsubsection{Mechanical treatment}

CNFs and CMFs are often produced by mechanical treatments of cellulose by means of a refiner and a high-pressure homogenizer (HPH). Additionally, techniques like microfluidization, high intensity ultrasonication or cryo-crushing are also used to scale down the cellulosic materials. Refining of fibers involves their introduction into the narrow gap between rotor and stator disks, fitted with bars and grooves, which fibrillate the fiber structure by gradually peeling off the external cell wall layers and exposing the inner layer. These exposed fibrils are now required to be treated in the homogenizer for obtaining the desirable nanoscale cellulosic fibrils [123].

Homogenizers can be used to force the fiber suspension through a small orifice at high pressure and shear cavitation forces resulting in a size reduction of the fibers to the nanoscale. This production process is quite simple and efficient, but still faces some drawbacks, like high energy consumption [123].

Microfluidization is an alternative mechanical treatment process in which the pulp slurry is introduced in a $Z$-shaped equipment. The device is similar to the high-pressure homogenizer, differing mainly in the 


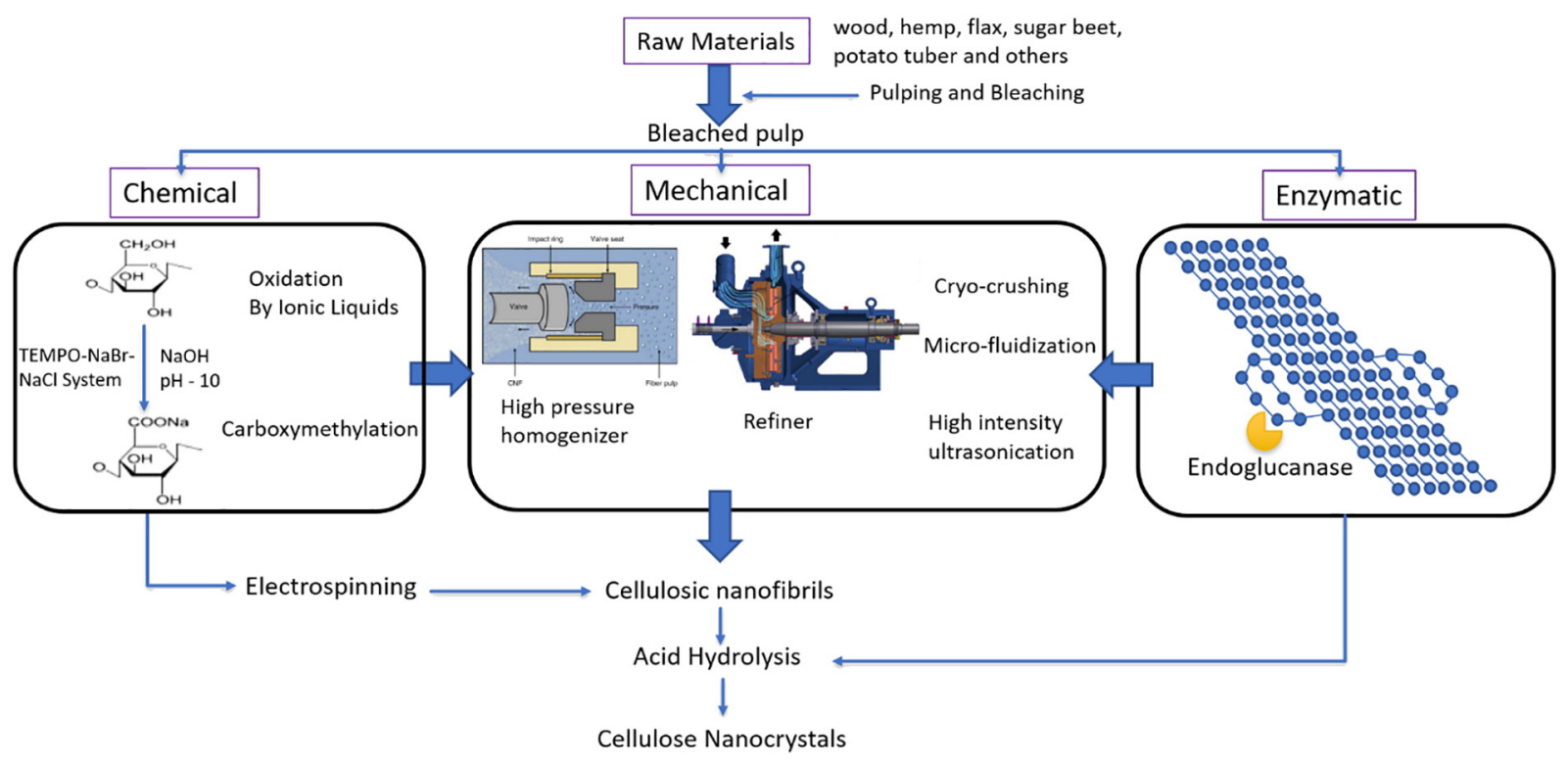

Fig. 6. Production methods for nanocellulose.

shape of the chamber and in the lack of moving parts, thus avoiding nozzle obstruction. Collisions between fibers split them into fibrils, followed by slurry acceleration, sending out the nanoscale fibers with a higher, and possibly more evenly distributed, degree of fibrillation [129].

High-intensity ultrasonication (HIU) is another way to obtain nanoscale fibers by ultrasound-induced and hydrodynamic forces, by using a mechanical oscillator that creates high-frequency waves. It was suggested that this process may produce too many microscale fibers, but it can be coupled with HPH or other treatments to uniformly acquire nanoscale fibrils [130]. The grinding treatment alone can degrade cellulose to the detriment of the reinforcing potential of NFC. That is why grinding is generally coupled with HPH or cryo-crushing [131,132]. Cryo-crushing involves the swelling of cellulosic fibers with water, which are then introduced in liquid nitrogen to make ice crystals. These crystals should be further treated by intense shear forces to break down the cell wall of the fibers [133-135]. Due to the high energy consumption of mechanical treatments, these techniques are not economical enough to be used in paper and paperboard industries $[129,136]$. Some papers even refer to energy values exceeding 30,000 $\mathrm{kWh}$ per ton of nanofibers produced [137].

Another issue is the low solid content (e.g., 1-2\%) resulting from the conventional production of CNFs or CMFs. Drying easily produces hornification, as fibrils collapse with each other, so the best option would be attaining high consistency during production. Recently, Bras' group (Grenoble) has been fruitfully investigating twin-screw extrusion, not only as means to attain very high solids contents (20\%), but also to build a path towards industrialization, allowing for continuous production processes $[138,139]$. An invention from the University of Maine in 2018 allows for a relatively high solids content (>4\%) and exceptionally low moisture content, as long as the liquid to which CNFs are associated is not water [140]. Essentially, the mechanical treatment is performed as usual, but along with an organic solvent like lactic acid or glycerol, and then a second solvent, more volatile than the first one, is used. Nevertheless, an organic co-solvent would likely be unacceptable for coating in paper mills.

\subsubsection{Enzymatic and chemical treatments}

Mechanical treatments require the pretreatment of cellulosic fibers to reduce the energy demand for the production of nanocellulose.
Most commonly, this involves reacting cellulose with enzymes or chemical agents, followed by HPH.

Earlier, pretreatment methods like acid hydrolysis and sonication were applied to obtain CNFs from cellulose I fibers. In this way, a network of weakly hydrogen-bonded rod-like cellulose elements was developed, but with a low aspect ratio (the ratio of width to height). Currently, to achieve the desired aspect ratio of nanoscale cellulose, the preferred way includes mild hydrolysis with endo-1,4- $\beta$-Dglucanase, as long as the structure of cellulose does not hinder its diffusion through the fiber $[123,141]$. The enzymatic treatment is a costefficient method for industries like paper and board [142], but, to the best of our knowledge, no work has dealt with the challenge of designing a continuous operation. For a more detailed analysis of the enzymatic production of nanocellulose, a recent study of Ribeiro et al. is referred [143].

Undoubtedly, the most successful chemical pretreatment to date is TEMPO (2,2,6,6-tetramethylpiperidine-1-oxyl) mediated oxidation. Typically, the primary oxidant system is $\mathrm{NaClO}$, with $\mathrm{NaBr}$ as co-catalyst. This system can be used for all kinds of cellulose, including native, regenerated and mercerized. The latter two become oxidized selectively at all primary hydroxyl groups, turned into carboxylic groups to constitute the water soluble polyglucuronic acid sodium salt. However, when native cellulose is used as feedstock, the degree of carboxylation is much lower [144,145].

Interestingly, the TEMPO-NaBr-NaClO system opens new ways to utilize the cellulose feedstock for the simultaneous production of CNFs and soluble poly(glucuronic acid). The degree of polymerization (DP) is generally affected by the amount of TEMPO, oxidation time and temperature [122,144]. Regarding the mechanism of the TEMPO-NaBr$\mathrm{NaClO}$ system, the 2,2,6,6-tetramethyl-1-pipelidinyloxy radical and the $\mathrm{NaBr}$ act as true catalysts. The latter is oxidized to $\mathrm{NaBrO}$ by reacting with $\mathrm{NaClO}$ and regenerated by reaction with the deprotonated nitroxyl group under alkaline conditions. As a consequence, the $-\mathrm{NO}^{-}$group of the former is oxidized to a nitrosonium cation (Scheme 6). This is the active oxidizing species, which converts glucopyranoside units into intermediate aldehydes and then to glucopyranosate. This leads to the regeneration of nitroxyl group. Oxycellulose is not reduced back to native cellulose, the same way that $\mathrm{NaCl}$ is not oxidized back to $\mathrm{NaClO}$ [146].

TEMPO-mediated oxidation can be coupled with a homogenizing mechanical treatment or sonication methods on native cellulose 
which has never been dried. From that, a transparent and highly viscous suspension of fibrils with an average width $3-5 \mathrm{~nm}$ can be obtained [147]. This transparency and viscosity are observed whenever the carboxylate content is at least $1.5 \mathrm{mmol} / \mathrm{g}$, with no intrinsic differences between never dried and once dried celluloses [148]. TEMPO-mediated oxidation was also used to produce nanoscale lignocellulosic materials from wheat straw [149].

$\mathrm{NaClO}_{2}$ has also been tested as a primary oxidant in aqueous media with $\mathrm{pH}$ ranging from 3.5 to 6.8. It resulted in less depolymerization of cellulose than when using hypochlorite, with an enhanced tensile strength of nanoscale fibrils [145,150].

Periodate-chlorite oxidation is a well-known pretreatment to improve the fibrillation efficiency of CNFs. In this pretreatment, sequential oxidation of the cellulose fibers with periodate and chlorite is used to obtain carbonyl groups on the $\mathrm{C} 2$ and $\mathrm{C} 3$ positions of anhydroglucose units. The oxidized celluloses with carbonyl contents ranging from 0.38 to $1.75 \mathrm{mmol} / \mathrm{g}$ could lead to forming highly viscous and transparent nanofibril gels, with yields of $85-100 \%$, without clogging the homogenizer [151]. Recently, the possibility of using ozonation along with a strong acid treatment was tested to produce CNFs from recycled paper sludge [152].

CNCs are generally produced from cellulosic materials in aqueous suspension with sulfuric acid, followed by intense mechanical or ultrasonic treatment. The amorphous region of the source material is dissolved in the highly acidic medium and the crystalline region can be separated from it to further obtain the CNCs. These are produced with a purity of approximately $90 \%$, with some anhydroglucose units esterified with sulfate groups. Fortunately, cellulose sulfate residues enhance the phase stability of CNCs in the aqueous medium, due to their negative charge [125].

\subsection{Applications of nanocellulose in papermaking}

The usefulness of nanoscale cellulose for papermaking is mainly due to its strong binding and barrier properties. Many applications of nanocellulose have already been identified at lab scale and are being increasingly implemented in paper mills. A recent industry review by Balea et al. [153] states that at least four very well-known paper companies are currently producing nanocellulose on site.

It is well-known that mechanical refining of pulp fibers makes them swell, enhances their flexibility and achieves a higher tensile strength due to an increase of inter-fiber H-bonds. H-bonding, and therefore strength, is improved further by the addition of nanocellulose in the pulp slurry. Nanocellulose can also be applied after the formation of the paper web, via coating, to enhance the printability and surface properties [154].

Due to the hydrophilicity of CNFs, poor compatibility with hydrophobic binders and slow dewatering in the paper machine might refrain

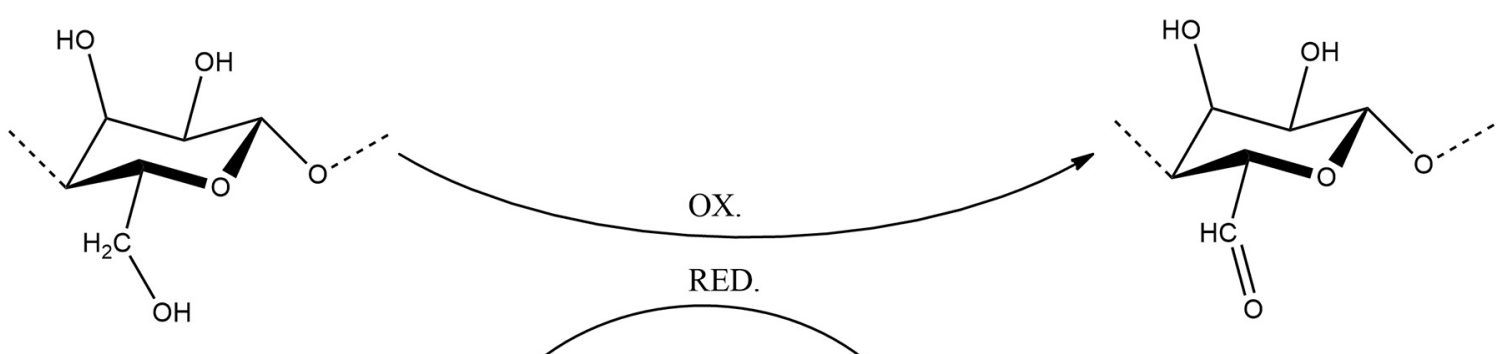

AGU
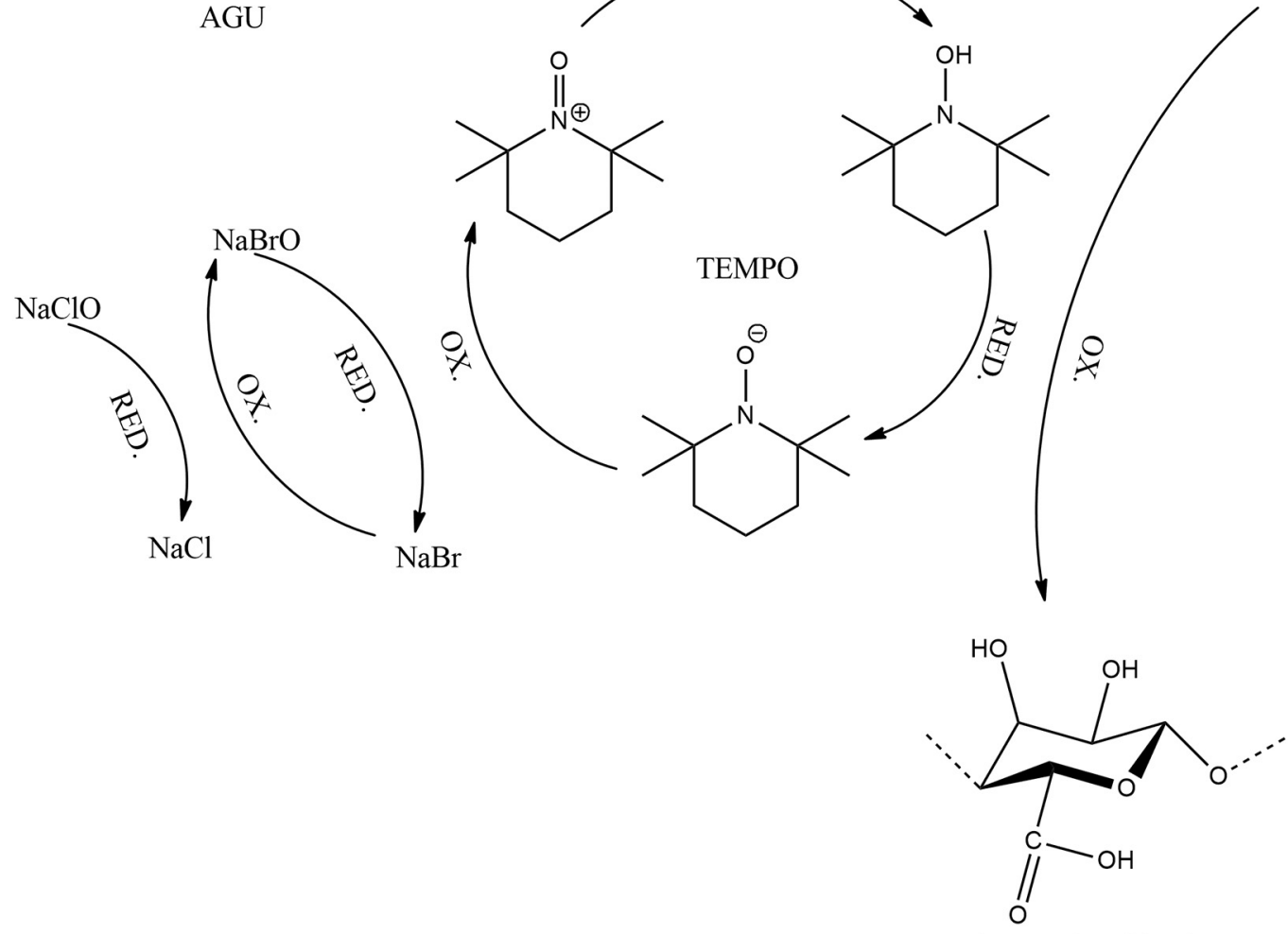

Glucuronic acid unit 
papermakers from using these nanoscale fibrils. However, alternative solutions involving chemical modification of CNFs and reduction in the number of hydroxyl groups have been suggested [155,156].

Recent research has proposed other promising nanoscale cellulosic materials. For instance, a nanocellulose film coated with a lignincarbohydrate complex was investigated for biomedical applications, as a biological carrier for the heart coronary artery endothelial cells [157]. Nanocelluloses can also replace, to a certain extent, carbon black from rubber in tires [158]. The latest review regarding the emerging application of nanocellulose film has been presented in $[159,160]$ and other possibilities of applications for nanocellulose combined with inorganic nanomaterials have been surveyed [115]. In this review, we have included most of the recent studies related to the application of nanocellulose materials in papermaking, starting from strengthening and flocculation in the wet end to surface applications while coating with nanocellulose.

\subsubsection{Wet end chemistry}

The introduction of nanocelluloses at the wet end of papermaking has been studied extensively because of their high mechanical strength. Before filtration, an appropriate amount of CNFs can be added to the furnish, along with mineral particles and retention aids. While nanocellulose enhances the tensile strength of paper, the drainability decreases because CNFs fill the pores of the wet paper web, resulting in a reduction in pore diameter [161-164].

In general, the paper substrate contains mineral fillers to save costs and to increase drying efficiency. They fill the voids between cellulose fibers and improve certain optical and structural properties, as well as printability. However, most fillers (PCC, GCC, talc, kaolin, and $\mathrm{TiO}_{2}$ ) have a negative influence on the tensile strength of paper, due to less inter-fiber bonding [165]. To overcome this problem, CNFs can be added in the wet end of a paper machine to retain good mechanical endurance while still achieving the improvement in optical properties provided by fillers [166].

A proportion of $10-40 \%$ of TEMPO-oxidized kraft pulp can be used to increase the wet tensile strength from 1.1 to $4.2 \mathrm{~N} \mathrm{~m} \mathrm{~g}^{-1}$ [167]. In that work, nonetheless, the pulp was not reduced to the nanoscale. The wet end addition of TEMPO-oxidized CNFs and fillers require an adequate amount of retention aid, which can act as a flocculant to retain these materials on the paper surface [168]. Interestingly, cationic polyacrylamide (C-PAM) not only helps to retain nanoscale oxycellulose, but also shows a synergistic effect to further increase the wet strength of paper, probably due to interactions between C-PAM and aldehyde groups of oxycellulose [169]. This synergy has also been proved for the flocculation of certain fillers, as the addition of TEMPO-oxidized CNFs to a kaolin suspension containing C-PAM produced an abrupt decrease of relative turbidity from 0.6 to nearly 0.05 [170]. A new finding of $\mathrm{CMFs}$ produced by an enzymatic treatment shows great flocculation efficiency of PCC while retaining a high DP, in comparison to the low DP of mechanical CMFs [141].

The presence of CNCs or surface-modified CNCs, similarly to the addition of CNFs, can increase the retention of fillers. However, while drainage is slowed down with the use of CNFs (as aforementioned), a slight improvement in the drainage rate was reported with highly oxidized CNCs [171]. In contrast, high degrees of oxidation of CNFs can decrease the retention of fillers, possibly due to their reduced flocculation during the wet end process [172].

To overcome the dewatering problem with the use of CNFs in papermaking, an adequate amount of C-PAM ( $0.1 \%)$, once again, can be added to the pulp slurry containing CNFs (1\%) [173]. This phenomenon is due to a decrease in the gel point of CNFs induced by polyelectrolytes such as C-PAM or polyethylenimine (PEI) [174]. Su et al. [175] suggested using polyamideamine-epichlorohydrin (PAE) while beating the pulp towards the mechanical production of CMFs. The drainage time increased with the addition of CMFs, but decreased from 349 to $180 \mathrm{~s}$ with $10 \mathrm{mg} /$ $\mathrm{g}$ of PAE.
In spite of the advantages of the wet end addition of CNFs, the increase in drainage time and the requirement of high specific energy still hinder their industrial usage [176]. To overcome these problems, CMFs produced by enzymatic treatment have been considered as good flocculating agents for fillers. Optimizing the dose of these CMFs (3\% enzymatic CMFs and $5 \%$ or more fillers) can resolve the problem of drainability [141].

\subsubsection{Paper coating}

Size press and bar coaters can be used for coating with CNFs/CMFs. Although the bar coater achieves a higher coating weight, the size press is indicated for two-side coating [177]. Another way to apply nanocellulose-containing coating formulations is the use of a spray coater over the surface of P\&W paper [178]. Improvements achieved by surface treatments are described in the following subsections.

5.3.2.1. Strengthening. Base paper can be sprayed with CNFs or CMFs containing suspensions to enhance the tensile strength. This can increase from $15 \mathrm{~N} \mathrm{~m} \mathrm{~g}^{-1}$ (base paper) to roughly $40 \mathrm{~N} \mathrm{~m} \mathrm{~g}^{-1}$ when using a CMF content up to $9 \%$, based on dry pulp weight [179]. These measured strength properties are not greatly affected by chemical modifications of fibrils, given that $\mathrm{H}$-bond formation is, in any case, the primary reason why the paper web is strengthened. Chitosan nanoparticles, along with the CNFs, were also used to improve the tensile strength of the paper substrate [180]. It is worth observing that manufacturing economical paper with high amounts of fillers benefits from the use of CNFs. The reduction of strength as a consequence of the filler content can be overcome with the addition of specific amounts of CNFs on the paper surface [181].

Lignin-containing nanocellulose shows higher tensile strength and elongation at break [181]. Lignin-poly(ethylene oxide) blends adhesion properties were also investigated by single lap joint method, concluding that the lignin content increases the shear strength via the formation of H-bonds with the nanocellulosic layer [182]. Moreover, other organic nanomaterials such as styrene-maleic anhydride copolymers synthesized by imidization contribute by improving the mechanical paper strength as well as printing and optical properties [183].

Nanocellulose, be it as CNFs or as CNCs, is also used along with cationic starches in the coating formulation for increasing the mechanical, barrier and optical properties of paper. A formulation comprising paper grade CS (95\%) and nanocrystals (5\%) produced a timid increase in the tensile index, from 45 to $54 \mathrm{~N} \mathrm{~m} \mathrm{~g}^{-1}$, but the improvement in air resistance (Gurley method) was impressive, from 46 to $721 \mathrm{~s}$ per $100 \mathrm{~mL}$ [184]. In contrast, a suspension of HCS and nanofibrils [185] resulted in a slight enhancement of air resistance, from 21 to roughly $55 \mathrm{~s}$ per $100 \mathrm{~mL}$, but the tensile index increased from 27.8 to $41.3 \mathrm{~N} \mathrm{~m} \mathrm{~g}^{-1}$. It would be hasty to infer from these data that CNFs necessarily have worse gas barrier properties than CNCs, since films fully consisting of CNFs show very little air permeability [186].

5.3.2.2. Barrier properties. Around 1940, cellulose-based paper coating agents were studied for the development of barrier properties of food packaging and greaseproof paper. An oil-proof aqueous coating composition was developed using water-soluble cellulose ethers [187,188]. William R. Collings and Harold C. Kelly developed greaseproof paper by coating with methylcellulose, sodium cellulose glycolate and hydroxyethylcellulose, besides plasticizers like sorbitol, ethyl sorbitol and glycerine [189]. Plasticizers such as bentonite along with starch [190], starch-silver nanoparticles [191], soybean oil-based coating materials plus other polymer emulsions [192], curdlan and chitosan [193], xylans [194], and nanocrystalline cellulose-AKD emulsion [43] were also tested in paper coating formulations to improve both barrier and mechanical properties.

Gas and oxygen barrier properties can be improved by the inclusion of CNFs in the coating solution [179], together with spin \& dip-coating methods [195]. However, as CNFs are very sensitive to moisture, their 
performance decreases under high relative humidity [196,197]. On the other hand, CNCs are less sensitive to moisture due to their highly crystalline structure, but still, CNCs show severe brittleness during coating [186,198].

A possible solution is the combined use of CNFs and CNCs as a multilayer coating to provide barrier properties to the paper for gas, oil and grease [199]. In this case, nanocellulose was not diluted in a starch matrix, so the improvement was astonishing: 1000 Gurley seconds with CNFs only, $\sim 4000 \mathrm{~s}$ with CNCs only, and $\sim 8000 \mathrm{~s}$ with a CNF/CNC bilayer. The study of multilayer coating of CNFs and shellac has also proven a reduced water vapor permeability $\left(6.5 \mathrm{~g} / \mathrm{m}^{2} 24 \mathrm{~h}\right)$, with a view for storing food with innovative, environmentally friendly cellulosic materials [200]. Another coating blend involved applying CNFs to a paper sheet precoated with modified calcium carbonate (MCC), increasing the holdup of nanoscale fibers. Smoothness and uniformity with controllable permeability were achieved with said combination [201].

Multilayer coating with polyelectrolytes on the surface of cellulosic fibers has also been identified as a favorable solution to densify the sheet, reduce shrinkage, and increase retention of solids. This technology can be utilized with the use of nanocellulose materials to get high strength paper with a reduction in the effluent load [176]. In another study, dissolved hydroxypropyl cellulose along with oxidized CNCs was found to be a strengthening agent, besides somehow increasing, although slightly, the vapor permeability of bagasse paper substrate [202]. This slight increase was more probably due to hydroxypropyl cellulose than to CNCs, since the latter have been consistently reported to decrease vapor permeability [186].

Modified CNFs have been recently used for enhancing the hydrophobicity during surface coating [203]. The authors also indicated the possibility of the dependency of the hydrophobic nature of these fibrils on their length, as shorter CNFs enhance the compactness of the surface, attaining a water contact angle of $164^{\circ}$ (instead of $138^{\circ}$ with longer fibrils).

Nanocelluloses with a bismuth complex were also studied for developing packaging solutions with antimicrobial properties. This complex showed a great tendency towards the inhibition of the growth of Gram-positive bacteria, at the same time that nanocellulose grants good barrier properties [204]. In this regard, the antimicrobial properties of quaternary ammonium groups are usually overlooked. It is reasonable to suggest that good barrier and antimicrobial properties could be granted, at the same time, by combining the two products highlighted in this review, highly-substituted CS and nanocellulose.

5.3.2.3. Printing quality. Nanocellulose can be used onto the paper surface to improve the printability, preferably combined with AKD. Hydrophilic CNFs can hold ink particles on the paper surface, while hydrophobic AKD contributes to the surface wet strength. This increases the print density and reduces print-through during ink-jet printing [205]. Still, the offset printing approach has setbacks for using CNFs as a replacement of petro-based binder in the coating layer, since the high absorption of water weakens the coated paper [11]. However, Imani et al. 2019 used lignin-containing nanocellulose to reduce the impact of water absorption during nanocellulosic coating [206].

Pei et al. (2013) developed cationic cellulose nanofibrils (DS 0.13) with an average width of 1.6 to $2.1 \mathrm{~nm}$ and a length of 1.3 to $2 \mathrm{~mm}$, and registered higher tensile strength, besides high dye absorption [207]. A patent assigned to the Zhejiang Sci-Tech University [208] also presents a preparation method for cationic nanocrystalline cellulose which, used along with starch and cationic styrene-acrylic emulsion, improves printability through paper coating. This invention also provides a better solution to use nanocellulose as a reinforcement agent in surface sized papermaking and reduces the use of synthetic latex.

Apart from plant-based nanocellulose, BC along with chitosan was also used in the paper coating formulation [209] for the improvement of surface, mechanical, optical, barrier and anti-microbial properties of paper. The printability of the cellulosic substrates was also improved due to an increase in the paper surface smoothness. Q. Chen et al. [210] used nanostarch with average particle size about $100 \mathrm{~nm}$ for paper surface applications as a coating adhesive. It was suggested that some amount of styrene-butadiene latex and an ordinary oxidized starch can be replaced by these nanostarches to achieve higher IGT printing surface strength and a glossier paper surface [210].

As any coating process including nanocelluloses will probably keep mineral pigments in the formulation, it is worth studying the interactions between them. CNFs can also be blended with kaolin on the paper surface to increase the print density with a laboratory flexographic press using water-based inks, but the ink absorption rate is reduced [211]. With one layer of PCC/CNFs and another layer of CNFs, the gamut area increased from 7055 to 8146 and black optical density went from 1.06 to 1.20 [212]. Even outside the paper industry, Hamada et al. [213] found consistent increases in the ink-jet printing properties for different fabrics after coating with a CNF suspension: for woven rayon, lightness decreased from 30.1 to 26.9 for black, from 65.7 to 59.4 for magenta, and from 54.1 to 51.1 for cyan.

Puceković et al. [12] coated the paper with CNCs and found an increase in surface gloss (from 2.65 to 4.09 gloss units) and print gloss (from 5.27 to 10.61 units). Likewise, the color density went from 0.34 when uncoated to 0.48 . They also observed that the CNC coating improves the drying time of vegetable oil-based ink [12]. No comparison with CNFs, more frequent in the literature, related to paper coating, was provided.

Simultaneous use of CNFs and starch (native or functionalized) as a coating layer on a base paper has been studied to reduce linting and dusting related problems during printing [214]. Fig. 7 depicts the primary mechanisms by which CS and CNFs interact with fibers.

\section{Technical, economic, environmental and legal considerations}

The use of lowly-substituted CS for surface sizing (or external sizing) is well established. In the absence of pigments, the solids content may be as low as $3 \%$ and the operation usually takes place in a film or size press placed right after pre-drying [215]. The suggested use of HCS and nanocellulose for the enhancement of printability, however, is that of pigment coating, aiming for a relatively high coat weight $(>3 \mathrm{~g}$ $\mathrm{m}^{-2}$ ). For that, the viscosity of the coating solution can be higher than $1 \mathrm{~Pa} \mathrm{~s}$, at least at low shear rates [216]. This clearly requires doctoring. High consistency, as long as the suspension is still runnable, is desirable to ease post-drying, especially considering the water holding capacity of nanocelluloses.

\subsection{Technical feasibility of surface treatments with nanocellulose and cat- ionic starch}

As aforementioned, the binder part of a coating formulation is often starch, synthetic latex or a blend thereof. Incorporating HCS and/or CNFs in the composition unavoidably alters the rheology and the runnability. This does not necessarily mean that current coaters are not valid, but papermakers need to make adjustments on the nip load, the doctor blade angle or pressure (or the pressure and hardness of the doctor bar), the application roll speed and/or any other operational factor. Everything should be carefully tested in a pilot plant. Curtain coating is out of the picture [217], as nanocellulose suspensions with high solids content do not spontaneously flow by gravity. On the other hand, spray coating may be useful for applying the nanocellulose on the surface of paper [218], by which the dewatering and post-drying problems may be resolved.

In any case, another troublesome question is related to film split/ metering: to what extent do HCS and CNFs undergo successful consolidation onto the substrate instead of following the rod or being doctored away? Once coated, dried, calendered and released to the market, will linting happen in inkjet printers? For HCS, attachment to paper is 
WITHOUT

a)
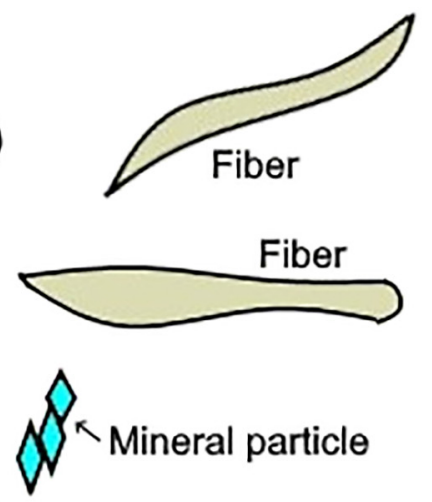

b)

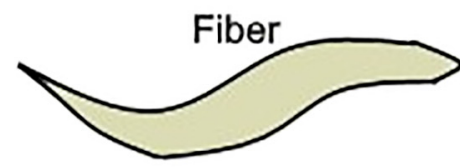

c)

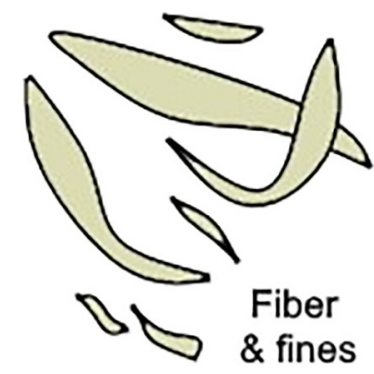

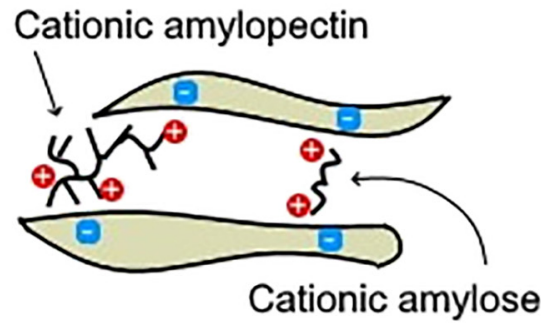
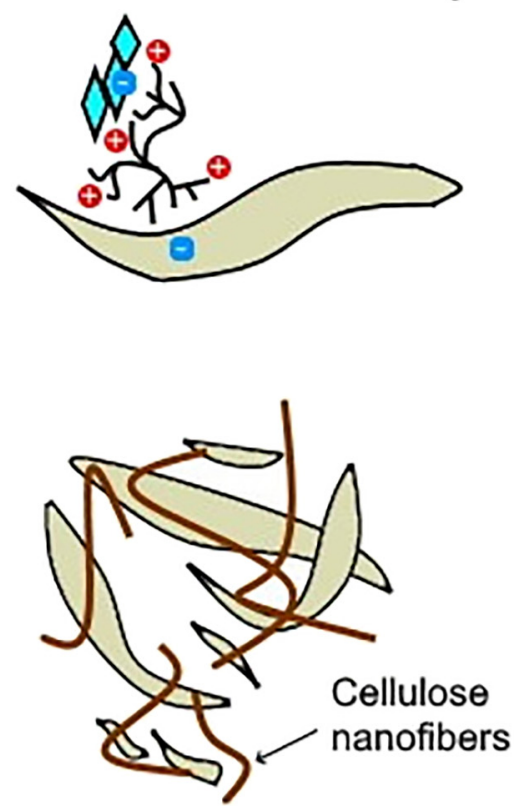

Fig. 7. Fibers, fines and mineral particles: electrostatic interactions upon the addition of cationic starch (a, b) and H-bonding with cellulose nanofibers (c).

favored by electrostatic interactions, but for nanocelluloses, conclusive data is still lacking. Even recent research reports the problem of impaired distributions and other pending limitations when depositing nanoscale cellulose on paper [206].

\subsection{Effect on production costs}

Currently, modified starches to be used in papermaking are purchased by the paper manufacturers from several companies. The modified starch market is valued above USD 9 billion, of which roughly a fifth corresponds to CS, and it has been growing over the past few years [219]. Cationic starches with higher DS would succeed only if papermakers are willing to pay more, after determining that the benefits outweigh the price increase. In order to minimize this price increase, and in spite of the wet method being used in most research papers, the dry or semidry cationization seems more feasible, at least for the near future. For instance, it has been mentioned that disrupting the crystallinity of starch by ball milling allows for DS values up to 0.3 [69]. The energy input required would be less costly than the addition of an organic anti-solvent, filtration and, especially, drying from moisture content that can be higher than $90 \%$.

Abbati de Assis et al. published a meticulous techno-economic assessment paper on CNC industrial production in 2017 [220] and a similar study on CNF/CMF in 2018 [221]. In both cases, they figured a plant capacity of $50 \mathrm{t} /$ day, operating 340 days per year. Taking into account not only the raw materials, but also water, electricity, the capital investment and contingency, the expected manufacturing costs were USD
3860-4940 per tonne (dry basis) for CNCs and 1493-1899 per tonne (dry basis) for CNFs/CMFs. While their hypotheses were plausible, those plants seem far away in time.

Current prices of CNFs, oxidized or not, range from USD 0.7 to 7 per gram, according to a recent review [222]. Such high prices are due to the lack of large scale nanocellulose production. If possible, both the pretreatment and mechanical treatment should be continuous. Adapting enzymatic hydrolysis, which is the most cost-efficient approach at the moment, to continuous operation is challenging, although the immobilization of glucanases is an interesting option [223]. Regarding the mechanical treatment, twin-screw extrusion can provide both continuous operation and a high solid content $[138,139]$. A CNF suspension whose consistency is as high as $20 \%$ cannot be used directly for coating, but it can be transported and then diluted when appropriate. Until the nanocellulose market reaches that point, CNFs and CMFs will be mostly produced in-situ, i.e., in the same paper mills where they will be used, with the quality and the solid content desired in each case [153].

\subsection{Environmental impact}

Farrell and Hauser [224], who have provided valuable insights into the cationization of cotton fabrics, put the alleged environmental advantages of these practices under question. The biggest problem lies with EPTAC, be it used directly or formed from CHPTAC. In fact, EPTAC is a "potent skin sensitizer and Carcinogen Class 2" [224].

Considerations regarding the origin of cationizing agents can also be added. Throughout this review, the potential of cationic starches to 
replace synthetic polyelectrolytes like C-PAM or PDADMAC is indeed positively valued. After all, both C-PAM and PDADMAC ultimately come from propylene (so they are petro-based chemicals) and are toxic to fish. However, CHPTAC (or EPTAC) comes from epichlorohydrin, whose industrial production implies, again, propylene.

When it comes to the biodegradability of CS, it is known to decrease with the increasing degree of substitution, and it is well documented that CS produced by etherification becomes non-biodegradable with $\mathrm{DS} \geq 0.54$ [225]. This is due to the antibacterial and antifungal activity of quaternary ammonium groups.

Life cycle assessment (LCA) of nanocellulose industrial production is not an easy task, given that the process is not even established. Still, researchers from Empa (Switzerland) [226] recently carried out a valuable LCA study on the basis of a scale-up model. This model is quite different from the ones mentioned in the previous section [220,221]. For example, its raw material is either whole carrot or carrot waste, and it implies a questionable functionalization that accounted for the highest environmental impact. Other than particular choices like that, heating and electricity consumption are the main contributors. A slightly previous LCA study [227] considered wood as raw material and, in the absence of pretreatment, pulp production and electricity consumption during the mechanical treatment (requiring a power supply of $108 \mathrm{MJ} / \mathrm{kg}$ ) implied the greatest impact. A pretreatment lowered the electricity needs to $8.4 \mathrm{MJ} /$ $\mathrm{kg}$ [227].

\subsection{European legislation}

A (still) informal alliance, aiming for "Green Recovery, has been recently launched in the European Parliament. European papermakers promptly supported the initiative [228]. This implies, among other consequences, a commitment to a globally sought reduction of plastics consumption [229].

Currently, the best available techniques (BAT) for manufacturing pulp and paper in the EU states were established by the European Commission Decision 2014/687/EU, of the 26th of September 2014. The document states that coating colors should be formulated so as to minimize emissions of volatile organic compounds. Moreover, papermakers are asked to recover as much of pigments and other coating components from the wastewater as possible, normally via a screeningflocculation-dewatering process. When recovery is not technically feasible, particles from the coating operation should undergo flocculation so they do not harm the subsequent biological wastewater treatment. Needless to say, this does not apply to readily biodegradable materials like most CS ethers or CNFs. The BAT-associated emission levels for total suspended solids have an upper limit of $0.35 \mathrm{~kg} / \mathrm{t}$ [230].

As of today, paper intended for food packaging must be coated in compliance with regulation 1935/2004 of the European Parliament and of the Council [231]. Besides the lists of authorized materials, any component which is a food additive by itself or that does not show detectable migration into food can be used, unless it is mutagenic, carcinogenic or toxic to reproduction. Şen et al. [232] propose using cationic starch to provide food packaging with antimicrobial properties, thus removing the need for specific antimicrobial agents. Even if these antimicrobial agents have been authorized, as in the case of silver, concerns involving ecotoxicity and increase of bacterial resistance have arisen [233].

\section{Challenges and future perspectives}

In 2018, the production of synthetic polymers, mainly derived from petroleum, was 359 million tonnes, about 3.2\% higher than in 2017 [229]. They include styrene-butadiene latex and C-PAM, widely used in paper mills. Now, it is essential to look for renewable sources as alternative raw materials to overcome the dependency on fossil resources [234-236]. While biobased polymers could relieve the environmental load, the large capital needs and the limited ability of the paper industry to price above marginal cost, mean that the alleged benefits do not usually outweigh the risks. For instance, the changes in drainability and pre-drying requirements that can arise from modifications in the wet end of the paper machine may require unaffordable additional investments. Hence, coating seems to provide a better opportunity to test the advantages of innovative solutions.

Can paper coating operations enhance the adaptability of new biobased materials? The answers are yet to be discovered for materials such as nanocellulose, due to their high absorption of water and production cost [155]. Plus, the rise of a powerful market for nanocellulose would depend on whether or not the pretreatment and the mechanical treatment can be done continuously, in a cost-efficient way and resulting in high solid content. This is not expected to happen soon. Generally, CNFs are produced from wood pulp and, due to the nature of their aqueous suspensions and to the difficulties of transportation, their production in integrated paper mills is, and most likely will continue, in the near future, to be dominant [153]. Therefore, there will be little market for paper grade nanocellulose, as most of the CNFs intended for paper coating will probably be produced on-site.

The only type of nanocellulose that seems likely to become widely used in paper mills, at least in the short run, is the micro- and nanofibrillar one. CNC production is too expensive and their tendency to brittleness hinders their utilization [198]. As for bacterial cellulose, as astonishing as some of its properties may be, its high cost, low solid content and its slow, batch-based production are definitely setbacks for papermakers. Nonetheless, it has great potential for biomedical applications and high-end products in general [116].

This is not to say that CNFs and CMFs do not present important setbacks, one of them being related to the desired uniformity for coating layers. They are harder to disperse than CNCs, tending to form clusters of fibrils [237]. This is yet another challenge to overcome, and it is not clear if it is better to address it via chemical modification of fibrils or via the addition of more agents. In any case, the growing interest from the paper industry is indicated by the growing number of patents assigned to companies, mainly from Japan, China and USA [238].

As counter-intuitive as it may seem, recent advances allow suggesting that the best opportunities for cationic starch lie in applications whose industrial usage is still not well established. In other words, cationic starch can be expected to make a true difference in areas other than bulk addition and surface sizing. The flocculation-aiding capabilities of cationic starch are currently used in wet end chemistry, but they can be even more interesting for detackification in recycling processes [96]. Regarding coating, the lack of substantial innovation in sizing over the past few years is compensated with the discovery of enhancements of printability. Hopefully, the recent research on new applications of CS will be soon translated into a greater diversity of paper grade cationic starches in the market.

\section{Conclusions}

The use of natural raw materials is generally regarded as a possible solution to relieve the environmental load. Still, simply aiming to replace petro-based binders or polyelectrolytes, while sticking to the traditional uses of paper, may fall short of ambition. HCS on paper surfaces could serve the three-fold aim of sizing, antimicrobial protection and color density enhancement. CNFs can allow for new functionalities of paper, towards thin, strong, flexible, air-resistant sheets with enhanced printability.

Of all the benefits of CS, the enhancement of printing quality was especially highlighted. However, when current commercially available cationic starches are used, these enhancements either do not surpass those achieved by petro-based polymers like PVA or PDADMAC, or need a much larger concentration of polysaccharide. Recent advances suggest that cationic starches with higher degrees of substitution, higher intrinsic viscosity (more branching or more molecular weight), 
or even different functional groups (esters instead of ethers) should be tested.

CNFs seem more promising for coating than for addition to the pulp slurry. The applications of CNFs in the wet end of the paper machine carry dewatering problems, at least increased drainage time, and may require too much energy for drying. Compensating the negative effect of the bulk addition of nanocellulose on drainage rate may require adding more C-PAM (or other polyelectrolytes) than usual.

When it comes to surface treatments, the setbacks that arise seem easier to overcome. In the first place, drying after coating uses much less energy than drying between the wet end and the surface treatment. Moreover, while the negative surface charge of both cellulose nanofibrils and fibers may result in linting if the former are not firmly bound to the latter, CNFs are not supposed to be the sole constituent of coating colors. We have indicated the advantages of combining both nanocellulose and HCS, along with the desired pigments, in the same formulation, as CNFs in a highly cationic starch matrix would become more easily bound to cellulose fibers.

\section{Acknowledgements}

This work was carried out under the Project inpactus-innovative products and technologies from eucalyptus, Project N..$^{\circ} 21874$ funded by Portugal 2020 through European Regional Development Fund (ERDF) in the frame of COMPETE $2020 \mathrm{n}^{\circ} 246 /$ AXIS II/2017. Authors would also like thank the Coimbra Chemical Centre, which is supported by the Fundação para a Ciência e a Tecnologia (FCT), through the projects UID/QUI/00313/2020 and COMPETE. M.S. acknowledges the PhD grant BDE 03|POCI-01-0247-FEDER-021874. R.A. acknowledges the post-doc grant BPD 02|POCI-01-0247-FEDER-021874.

\section{Declaration of competing interest}

The authors declare no conflicts of interest.

\section{References}

[1] R. Dooley, Paper Beats Digital in Many Ways, According to Neuroscience, Forbes, 2015.

[2] U. Forsström, Interactions between Base Paper and Coating Color in Metered Size Press Coating, Helsinki University of Technology, Espoo, Finland, 2003.

[3] J. Gigac, M. Stankovská, M. Letko, E. Opálená, Effect of surface properties of base paper on print quality, Wood Res 59 (2014) 717-730.

[4] J. Gigac, M. Stankovská, E. Opálená, A. Pažitný, The effect of pigments and binders on inkjet print quality, Wood Res 61 (2016) 215-226.

[5] K.W. Howard, K.T. Hodgson, Influence of pigment packing behavior on the adhesive requirements of aqueous paper coatings, J. Coatings Technol. Res. (2015) https://doi.org/10.1007/s11998-014-9645-0.

[6] H.-K. Lee, M. Joyce, P.D. Fleming, Influence of pigment particles on gloss and printability for inkjet paper coatings, Int. Conf. Digit. Print. Technol 2004, pp. 934-939.

[7] E. Caner, R. Farnood, N. Yan, Effect of the coating formulation on the gloss properties of coated papers, Int. Print. Graph. Arts Conf. Miami FL, 2006.

[8] V.K. Rastogi, P. Samyn, Bio-based coatings for paper applications, Coatings (2015) https://doi.org/10.3390/coatings5040887.

[9] S. Sousa, A.M. de Sousa, B. Reis, A. Ramos, Influence of binders on inkjet print quality, Mater. Sci. 20 (2014) 55-60.

[10] R. Bardet, J. Bras, Cellulose Nanofibers and their Use in Paper Industry, 2014https:// doi.org/10.1142/9789814566469 0013.

[11] S. Nygårds, Nanocellulose in Pigment Coatings - Aspects of Barrier Properties and Printability in Offset, Linköping University, 2011.

[12] N. Puceković, A. Hooimeijer, B. Lozo, Cellulose nanocrystals coating - a novel paper coating for use in the graphic industry, Acta Graph 26 (2015) 21-26.

[13] A. Chemelli, F. Gomernik, F. Thaler, A. Huber, U. Hirn, W. Bauer, S. Spirk, Cationic starches in paper-based applications-a review on analytical methods, Carbohydr. Polym. (2020)https://doi.org/10.1016/j.carbpol.2020.115964.

[14] H. Li, Y. Qi, Y. Zhao, J. Chi, S. Cheng, Starch and its derivatives for paper coatings: a review, Prog. Org. Coatings. (2019)https://doi.org/10.1016/j.porgcoat.2019.05.015.

[15] R. Sangl, W. Auhorn, W. Kogler, M. Tietz, Surface sizing and coating, Handb. Pap. Board, John Wiley \& Sons, Ltd 2013, pp. 745-784.

[16] M.A. Hubbe, R.A. Gill, Fillers for papermaking: a review of their properties, usage practices, and their mechanistic role, BioResources 11 (2016) 2886-2963.

[17] N. Kumar, N.K. Bhardwaj, S.K. Chakrabarti, S. Kumar, Synthesis and application of calcium sulphate pigment for paper coating: potential and prospects, Powder Technol. 218 (2012) 40-45.
[18] A.K. Singhal, S. Kumar, S. Gupta, N.K. Bhardwaj, R. Varadhan, Calcium sulphate as pigment for improved functional properties of coated paper, Prog. Org. Coatings. 79 (2015) 31-36.

[19] S. Yoo, J.S. Hsieh, P. Zou, J. Kokoszka, Utilization of calcium carbonate particles from eggshell waste as coating pigments for ink-jet printing paper, Bioresour. Technol. 100 (2009) 6416-6421.

[20] H. Al-Turaif, Surface coating properties of different shape and size pigment blends, Prog. Org. Coatings. 65 (2009) 322-327.

[21] Y. Zou, J.S. Hsieh, E. Mehnert, J. Kokoszka, The effect of pigments and latices on the properties of coated paper, Colloids Surfaces A Physicochem. Eng. Asp. 294 (2007) 40-45.

[22] Y. Zhu, D. Bousfield, W.M. Gramlich, The influence of pigment type and loading on water vapor barrier properties of paper coatings before and after folding, Prog. Org. Coatings. 132 (2019) 201-210.

[23] A. Sand, M. Toivakka, T. Hjelt, Influence of colloidal interactions on pigment coating layer structure formation, J. Colloid Interface Sci. 332 (2009) 394-401.

[24] E. Lehtinen, Coating binders - general, in: E. Lehtinen, H.U. of Technology (Eds.), Pigment Coat. Surf. Sizing Pap, 1st ed.Finnish Paper Engineers' Association and TAPPI 2000, pp. 108-112.

[25] S. Cheng, Y. Zhao, Y. Wu, Surfactant-free hybrid latexes from enzymatically hydrolyzed starch and poly(butyl acrylate-methyl methacrylate) for paper coating, Prog. Org. Coatings. 118 (2018) 40-47.

[26] R. Anthony, Z. Xiang, T. Runge, Paper coating performance of hemicellulose-rich natural polymer from distiller's grains, Prog. Org. Coatings. 89 (2015) 240-245.

[27] A. Ortner, K. Hofer, W. Bauer, G.S. Nyanhongo, G.M. Guebitz, Laccase modified lignosulfonates as novel binder in pigment based paper coating formulations, React. Funct. Polym. 123 (2018) 20-25.

[28] Y. Du, J. Liu, B. Wang, H. Li, Y. Su, The influence of starch-based bio-latex on microstructure and surface properties of paper coating, Prog. Org. Coatings. 116 (2018) 51-56.

[29] S. Di Risio, N. Yan, Characterizing coating layer z-directional binder distribution in paper using atomic force microscopy, Colloids Surfaces A Physicochem. Eng. Asp. 289 (2006) 65-74.

[30] Y. Du, J. Liu, J. Wang, B. Wang, H. Li, Y. Su, Starch-based bio-latex redistribution during paper coating consolidation, Prog. Org. Coatings. 106 (2017) 155-162.

[31] K. Matilainen, T. Hämäläinen, A. Savolainen, T. Sipiläinen-Malm, J. Peltonen, T. Erho, M. Smolander, Performance and penetration of laccase and ABTS inks on various printing substrates, Colloids Surfaces B Biointerfaces 90 (2012) 119-128.

[32] M. Tielemans, P. Roose, Study of the rheology of aqueous radiation curable polyurethane dispersions modified with associative thickeners, Prog. Org. Coatings. 63 (2008) 182-188.

[33] O. Quadrat, J. Horský, L. Mrkvičková, J. Mikešová, J. Šňupárek, Thickening of butyl acrylate/styrene/2-hydroxyethyl methacrylate/acrylic acid latices with an HEUR associative thickener, Prog. Org. Coatings. 42 (2001) 110-115.

[34] L.-M. Zhang, Cellulosic associative thickeners, Carbohydr. Polym. 45 (2001) 1-10.

[35] T. Svanholm, B. Kronberg, F. Molenaar, Adsorption studies of associative interactions between thickener and pigment particles, Prog. Org. Coatings. 30 (1997) 167-171.

[36] H. Liang, Z. Long, S. Yang, L. Dai, Organic modification of bentonite and its effect on rheological properties of paper coating, Appl. Clay Sci. 104 (2015) 106-109.

[37] C. Liu, H. Du, L. Dong, X. Wang, Y. Zhang, G. Yu, B. Li, X. Mu, H. Peng, H. Liu, Properties of nanocelluloses and their application as rheology modifier in paper coating, Ind. Eng. Chem. Res. (2017)https://doi.org/10.1021/acs.iecr.7b01804.

[38] M.A. Hubbe, P. Tayeb, M. Joyce, P. Tyagi, M. Kehoe, K. Dimic-Misic, L. Pal, Rheology of nanocellulose-rich aqueous suspensions: a review, BioResources (2017)https:// doi.org/10.15376/biores.12.4.Hubbe.

[39] J. Ahlgren, Pigment coating and surface sizing of paper, in: Esa Lehtinen, H.U. of Technology (Eds.), Pap. Mak. Sci. Technol. Ser. B. 11, 1st ed.Finnish Paper Engineers' Association and TAPPI 2000, pp. 170-176.

[40] G. Tari, J.M.. Ferreira, Colloidal processing of calcium carbonate, Ceram. Int. 24 (1998) 527-532.

[41] E. Vorobiev, T. Mouroko-Mitoulou, Z. Soua, Precoat filtration of a deflocculated mineral suspension in the presence of a dispersant, Colloids Surfaces A Physicochem. Eng. Asp. 251 (2004) 5-17.

[42] F. Touaiti, M. Pahlevan, R. Nilsson, P. Alam, M. Toivakka, M.P. Ansell, C.E. Wilen, Impact of functionalised dispersing agents on the mechanical and viscoelastic properties of pigment coating, Prog. Org. Coatings. 76 (2013) 101-106.

[43] L. Yang, S. Lu, J. Li, F. Zhang, R. Cha, Nanocrystalline cellulose-dispersed AKD emulsion for enhancing the mechanical and multiple barrier properties of surface-sized paper, Carbohydr. Polym. 136 (2016) 1035-1040.

[44] L. Heikkilä, A. Tømmerås, T. Engels, E. Knudsen, Coating additives, in: E. Lehtinen, H.U. of Technology (Eds.), Pigment Coat. Surf. Sizing Pap, 1st ed.Finnish Paper Engineers' Association and TAPPI 2000, pp. 160-170.

[45] W. Scholz, W. Kamutzi, R. Pelzer, Crosslinking Agents for Paper Coating, 2007 50-54.

[46] P. Bajpai, Optical Properties of Paper, Biermann's Handb. Pulp Pap, 2018 237-271.

[47] S. Serroukh, P. Huber, A. Lallam, Adsorption behavior of optical brightening agent on microfibrillated cellulose studied through inverse liquid chromatography: the need to correct for axial dispersion effect, J. Chromatogr. A 1533 (2018) 17-29.

[48] G. Zhang, H. Zheng, M. Guo, L. Du, G. Liu, P. Wang, Synthesis of polymeric fluorescent brightener based on coumarin and its performances on paper as light stabilizer, fluorescent brightener and surface sizing agent, Appl. Surf. Sci. 367 (2016) $167-173$.

[49] G. Zhang, M. Guo, Y. Ma, L. Du, J. Pei, G. Liu, Preparation of 4,4'-diaminostilbene2,2'-disulfonic acid derivative/PVA/LDHs composite fluorescent brightener and performances on paper surface, Appl. Surf. Sci. 466 (2019) 715-723. 
[50] K. Takeshita, Lubricant for paper coating, JapanTAPPI J. 53 (1999) 1179-1185 53.

[51] D. Licursi, C. Antonetti, M. Martinelli, E. Ribechini, M. Zanaboni, A.M. Raspolli Galletti, Monitoring/characterization of stickies contaminants coming from a papermaking plant - toward an innovative exploitation of the screen rejects to levulinic acid, Waste Manag. (2016)https://doi.org/10.1016/j.wasman.2016.01. 026.

[52] Q. Wen, Z. Chen, Y. Zhao, H. Zhang, Y. Feng, Biodegradation of polyacrylamide by bacteria isolated from activated sludge and oil-contaminated soil, J. Hazard. Mater. 175 (2010) 955-959.

[53] S. Sängerlaub, M. Brüggemann, N. Rodler, V. Jost, K.D. Bauer, Extrusion coating of paper with poly(3-hydroxybutyrate-co-3-hydroxyvalerate) (PHBV)-packaging related functional properties, Coatings 9 (2019) 1-28.

[54] C. Dang, M. Xu, Y. Yin, J. Pu, Preparation and characterization of hydrophobic noncrystal microporous starch (NCMS) and its application in food wrapper paper as a sizing agent, BioResources 12 (2017) 5775-5789.

[55] R. Nigmatullin, V. Gabrielli, J.C. Muñoz-García, A.E. Lewandowska, R. Harniman, Y.Z. Khimyak, J. Angulo, S.J. Eichhorn, Thermosensitive supramolecular and colloidal hydrogels via self-assembly modulated by hydrophobized cellulose nanocrystals, Cellulose 26 (2019) 529-542.

[56] J. Song, O.J. Rojas, Approaching super-hydrophobicity from cellulosic materials: a review, Nord. Pulp Pap. Res. J. 28 (2013) 216-238.

[57] EU starch market data - 2018. , Starch.EU, 2018.

[58] J. BeMiller, R. Whistler, History and future of starch, Starch Chem. Technol, Elsevier Inc 2009, pp. 1-10.

[59] S.C. Alcázar-Alay, M.A.A. Meireles, Physicochemical properties, modifications and applications of starches from different botanical sources, Food Sci. Technol. 35 (2015) 215-236, https://doi.org/10.1590/1678-457X.6749.

[60] C. Chiu, D. Solare, Modification of starches, Starch Chem. Technol, Third EditElsevier Inc 2009, pp. 629-648.

[61] A. Tara, F. Berzin, L. Tighzert, B. Vergnes, Preparation of cationic wheat starch by twin-screw reactive extrusion, J. Appl. Polym. Sci. 93 (2004).

[62] M.I. Khalil, S. Farag, Preparation of some cationic starches using the dry process, Starch - Stärke 50 (1998) 267-271.

[63] A. Pfeifer, R. Hampe, T. Heinze, Synthesis and characterization of novel watersoluble and bactericidic cationic starch esters, Starch/Stärke 69 (2017) 1-8.

[64] T. Heinze, V. Haack, S. Rensing, Starch derivatives of high degree of functionalization. 7. Preparation of cationic 2hydroxypropyltrimethylammonium chloride starches, Starch/Stärke 56 (2004) 288-296.

[65] G. Hellwig, D. Bischoff, A. Rubo, Hanau, Production of cationic starch ethers using an improved dry process, Starch/Staerke. 44 (1992) 69-74.

[66] N. Masina, Y.E. Choonara, P. Kumar, L.C. Toit, M. Govender, S. Indermun, V. Pillay, A review of the chemical modification techniques of starch, Carbohydr. Polym. 157 (2017) 1226-1236.

[67] S. Radosta, W. Vorwerg, A. Ebert, A.H. Begli, D. Grülc, M. Wastyn, Properties of lowsubstituted cationic starch derivatives prepared by different derivatisation processes, Starch/Stärke 56 (2004) 277-287.

[68] S. Santacruz, Characterisation of cationic potato starch by asymmetrical flow fieldflow fractionation. Influence of ionic strength and degree of substitution, Carbohydr. Polym. 106 (2014) 166-171.

[69] Y. Su, H. Du, Y. Huo, Y. Xu, J. Wang, L. Wang, S. Zhao, S. Xiong, Characterization of cationic starch flocculants synthesized by dry process with ball milling activating method, Int. J. Biol. Macromol. 87 (2016) 34-40.

[70] H.J. Prado, M.C. Matulewicz, Cationization of polysaccharides: a path to greener derivatives with many industrial applications, Eur. Polym. J. 52 (2014) 53-75.

[71] T. Vihervaara, H.H. Bruun, R. Backman, M. Paakkanen, The effect of different methods of cationisation on the starch granule and its gelatinisation product, Starch - Stärke 42 (1990) 64-68.

[72] S. Pal, D. Mal, R.P. Singh, Cationic starch: an effective flocculating agent, Carbohydr. Polym. 59 (2005) 417-423.

[73] V. Haack, T. Heinze, G. Oelmeyer, W.M. Kulicke, Starch derivatives of high degree of functionalization, 8 synthesis and flocculation behavior of cationic starch polyelectrolytes, Macromol. Mater. Eng. 287 (2002) 495-502.

[74] J. Bendoraitiene, R. Kavaliauskaite, R. Klimaviciute, A. Zemaitaitis, Peculiarities of starch cationization with glycidyltrimethylammonium chloride, Starch - Stärke 58 (2006) 623-631.

[75] EU, Risk Assessment Report: Epoxypropyltrimethylammonium Chloride, 2007.

[76] A. Hebeish, A. Higazy, A. El-Shafei, S. Sharaf, Synthesis of carboxymethyl cellulose (CMC) and starch-based hybrids and their applications in flocculation and sizing, Carbohydr. Polym. 79 (2010) 60-69.

[77] R. Auzély-Velty, M. Rinaudo, Synthesis of starch derivatives with labile cationic groups, Int. J. Biol. Macromol. 31 (2003) 123-129.

[78] H. Granö, J. Yli-Kauhaluoma, T. Suortti, J. Käki, K. Nurmi, Preparation of starch betainate: a novel cationic starch derivative, Carbohydr. Polym. 41 (2002) 277-283.

[79] C.L. Mehltretter, T.E. Yeates, G.E. Hamerstrand, B.T. Hofreiter, C.E. Rist, Preparation of cationic dialdehyde starches for wet strength paper, Tappi 45 (1962) 750-752.

[80] L. Quanxiao, L. Jinli, X. Wencai, Application of cationic starch with high degree of substitution in packaging paper from high yield pulp, 17th IAPRI World Conf. Packag 2010, pp. 35-38.

[81] R. Kavaliauskaite, R. Klimaviciute, A. Zemaitaitis, Factors influencing production of cationic starches, Carbohydr. Polym. 73 (2008) 665-675.

[82] J. Bendoraitiene, R. Klimaviciute, A. Zemaitaitis, Preparation of high-substituted cationic starch in presence of organic bases, Starch/Stärke 64 (2012) 696-703.

[83] Y. Wang, W. Xie, Synthesis of cationic starch with a high degree of substitution in an ionic liquid, Carbohydr. Polym. 80 (2010) 1172-1177.
[84] N. Odabas, H. Amer, U. Henniges, A. Potthast, T. Rosenau, A comparison of methods to quantify cationization of cellulosic pulps, J. Wood Chem. Technol. 37 (2017) $136-147$.

[85] V. Becerra, J. Odermatt, Direct determination of cationic starches in paper samples using analytical pyrolysis, J. Anal. Appl. Pyrolysis 105 (2014) 348-354.

[86] K. Niegelhell, A. Chemelli, J. Hobisch, T. Griesser, H. Reiter, U. Hirn, S. Spirk, Interaction of industrially relevant cationic starches with cellulose, Carbohydr. Polym. 179 (2018) 290-296.

[87] H. Petersen, S. Radosta, W. Vorwerg, B. Kießler, Cationic starch adsorption onto cellulosic pulp in the presence of other cationic synthetic additives, Colloids Surfaces A Physicochem. Eng. Asp. 433 (2013) 1-8.

[88] J. Liu, R. Yang, F. Yang, Effect of the starch source on the performance of cationic starches having similar degree of substitution for papermaking using deinked pulp, BioResources 10 (2015) 922-931.

[89] K. Vaezi, G. Asadpour, H. Sharifi, Effect of $\mathrm{ZnO}$ nanoparticles on the mechanical, barrier and optical properties of thermoplastic cationic starch/montmorillonite biodegradable films, Int. J. Biol. Macromol. 124 (2019) 519-529.

[90] A. Ashori, N. Cordeiro, M. Faria, Y. Hamzeh, Effect of chitosan and cationic starch on the surface chemistry properties of bagasse paper, Int. J. Biol. Macromol. 58 (2013) 343-348.

[91] L. Quanxiao, L. Jinli, X. Wencai, L. Yubin, Research on application of high degree of substitution cationic starch in paper coating, Adv. Mater. Res. 287-290 (2011) 2074-2077.

[92] M. Björklund, L. Wågberg, Flocculation of cellulosic fibres following addition of cationic starch, Colloids Surfaces A Physicochem. Eng. Asp. 105 (1995) 199-209.

[93] M. Zhang, B. Ju, S. Zhang, X. Li, Flocculation behavior of starch betainate, Int. Conf. Mater. Eng. Appl. (ICMEA 2015) 2015, pp. 694-699.

[94] X. Wang, Population balance modeling of precipitated calcium carbonate (PCC) flocculation induced by cationic starches, Int. J. Miner. Process. 148 (2016) 9-14.

[95] G. Petzold, L. Schönberger, S. Genest, S. Schwarz, Interaction of cationic starch and dissolved colloidal substances from paper recycling, characterized by dynamic surface measurements, Colloids Surfaces A Physicochem. Eng. Asp. 413 (2012) 162-168.

[96] Q.Q. Chen, J.K. Yuan, Q. Shen, Z. Dong, Method and Composition for Detackifying Organic Contaminants in the Process of Pulping and Papermaking. US20150159328A1, 2015.

[97] H. Zhou, L. Zhou, X. Yang, Optimization of preparing a high yield and high cationic degree starch graft copolymer as environmentally friendly flocculant: through response surface methodology, Int. J. Biol. Macromol. 118 (2018) 1431-1437.

[98] Q. Lin, S. Qian, C. Li, H. Pan, Z. Wu, G. Liu, Synthesis, flocculation and adsorption performance of amphoteric starch, Carbohydr. Polym. 90 (2012) 275-283.

[99] E. Lekniute, L. Peciulyte, R. Klimaviciute, J. Bendoraitiene, A. Zemaitaitis, Structural characteristics and flocculation properties of amphoteric starch, Colloids Surfaces A Physicochem. Eng. Asp. 430 (2013) 95-102.

[100] J. Matusiak, E. Grządka, Cationic starch as the effective flocculant of silica in the presence of different surfactants, Sep. Purif. Technol. 234 (2020), 116132.

[101] L. You, F. Lu, D. Li, Z. Qiao, Y. Yin, Preparation and flocculation properties of cationic starch/chitosan crosslinking-copolymer, J. Hazard. Mater. 172 (2009) 38-45.

[102] T. Yun, B. Pang, J. Lu, Y. Lv, Y. Cheng, H. Wang, Study on the derivation of cassava residue and its application in surface sizing, Int. J. Biol. Macromol. 128 (2019) 80-84.

[103] F. Chen, H. Wu, D. Liu, P. You, Preparation Method of High-substitution-Degree Cationic Starch Modification Alkyl Ketene Dimer (AKD), CN102535247, 2012.

[104] Y. Chuanmeng, Starch-Based Cationic Surface Sizing Agent and Preparation Method Thereof, CN109208381, 2019.

[105] B. Gong, W. Liu, X. Zhang, H. Wang, D. Yu, G. Li, Z. Song, Preparation of starch and laponite co-stabilized alkenyl succinic anhydride emulsions for paper sizing, J. Dispers. Sci. Technol. (2017)https://doi.org/10.1080/01932691.2016.1178586.

[106] A. Lundberg, J. Ortegren, Improved Print Quality by Surface Fixation of Pigments, 2010.

[107] M. Stankovská, J. Gigac, M. Letko, E. Opálená, The effect of surface sizing on paper wettability and on properties of inkjet prints, Wood Res 59 (2014) 67-76.

[108] H.L. Lee, J.Y. Shin, C.-H. Koh, H. Ryu, D.-J. Lee, C. Sohn, Surface sizing with cationic starch: its effect on paper quality and the papermaking process, TAPPI J. 1 (2002) 34-40.

[109] T.T. Lamminmäki, J.P. Kettle, P.A.C. Gane, Absorption and adsorption of dye-based inkjet inks by coating layer components and the implications for print quality, Colloids Surfaces A Physicochem. Eng. Asp. 380 (2011) 79-88.

[110] C. Hanbin, L. Juan, Z. Jiali, Preparation Method for Writing Paper, CN102852041, 2013.

[111] M. Knaapila, B. Stewart, T. Costa, S.E. Rogers, J. Pragana, S.M. Fonseca, A.J.M. Valente, M.L. Ramos, D. Murtinho, J.C. Pereira, R. Mallavia, H.D. Burrows, Incorporation of a cationic conjugated polyelectrolyte CPE within an aqueous poly(vinyl alcohol) sol, Macromolecules 49 (2016) 9119-9131.

[112] J.G.C. Baptista, S.P.J. Rodrigues, A.F.Y. Matsushita, C. Vitorino, T.M.R. Maria, H.D Burrows, A.A.C.C. Pais, A.J.M. Valente, Does poly(vinyl alcohol) act as an amphiphilic polymer? An interaction study with simvastatin, J. Mol. Liq. 222 (2016) 287-294.

[113] J. Gigac, M. Stankovská, M. Fišerová, E. Opálená, Improvement of inkjet print quality via hydrophilic polymers and base paper, Wood Res 60 (2015) 739-746.

[114] K. Totani, R. Shimizu, Y. Takiyama, Inkjet Recording Paper Sheet, JP2014087987A, 2012.

[115] Q. Zhang, L. Zhang, W. Wu, H. Xiao, Methods and applications of nanocellulose loaded with inorganic nanomaterials: a review, Carbohydr. Polym. 229 (2020).

[116] C. Sharma, N.K. Bhardwaj, Bacterial nanocellulose: present status, biomedical applications and future perspectives, Mater. Sci. Eng. C. 104 (2019). 
[117] S. Salimi, R. Sotudeh-Gharebagh, R. Zarghami, S.Y. Chan, K.H. Yuen, Production of nanocellulose and its applications in drug delivery: a critical review, ACS Sustain. Chem. Eng. 7 (2019) 15800-15827.

[118] E. Sjöström, Wood Chemistry: Fundamentals and Applications, 2nd ed. Academic Press, INC, 1993.

[119] A. Isogai, Review development of completely dispersed cellulose nano fi bers, 94 (2018) 161-179.

[120] M. Rajinipriya, M. Nagalakshmaiah, M. Robert, S. Elkoun, Importance of agricultural and industrial waste in the Field of Nanocellulose and recent industrial developments of wood based Nanocellulose: a review, ACS Sustain. Chem. Eng. 6 (2018) 2807-2828.

[121] D. Klemm, F. Kramer, S. Moritz, T. Lindström, M. Ankerfors, D. Gray, A. Dorris, Nanocelluloses: a new family of nature-based materials, Angew. Chemie - Int Ed. 50 (2011) 5438-5466.

[122] A. Isogai, Wood nanocelluloses: fundamentals and applications as new bio-based nanomaterials, J. Wood Sci. 59 (2013) 449-459.

[123] H.P.S.A. Khalil, Y. Davoudpour, M.N. Islam, A. Mustapha, K. Sudesh, R. Dungani, M. Jawaid, Production and modification of nanofibrillated cellulose using various mechanical processes: a review, Carbohydr. Polym. 99 (2014) 649-665.

[124] E.H. Qua, P.R. Hornsby, H.S.S. Sharma, G. Lyons, Preparation and characterisation of cellulose nanofibres, J. Mater. Sci. 46 (2011) 6029-6045.

[125] Y. Habibi, L.A. Lucia, O.J. Rojas, Cellulose nanocrystals: chemistry, self-assembly, and applications, Chem. Rev. 110 (2010) 3479-3500.

[126] H. Kargarzadeh, M. Ioelovich, I. Ahmad, S. Thomas, A. Dufresne, Methods for extraction of nanocellulose from various sources, Handb. Nanocellulose Cellul. Nanocomposites 2017, pp. 1-49.

[127] D.J. Gardner, G.S. Oporto, R. Mills, M.A.S.A. Samir, Adhesion and surface issues in cellulose and nanocellulose, J. Adhes. Sci. Technol. 22 (2008) 545-567.

[128] D. Klemm, D. Schumann, F. Kramer, N. Heßler, M. Hornung, H.-P. Schmauder, S. Marsch, Nanocelluloses as innovative polymers in research and application, Adv. Polym. Sci. (2006) 49-96.

[129] S.H. Osong, S. Norgren, P. Engstrand, Processing of wood-based microfibrillated cellulose and nanofibrillated cellulose, and applications relating to papermaking: a review, Cellulose 23 (2016) 93-123.

[130] S. Wang, Q. Cheng, A novel process to isolate fibrils from cellulose fibers by highintensity ultrasonication, part 1: process optimization, J. Appl. Polym. Sci. 113 (2009) 1270-1275.

[131] I. Siró, D. Plackett, Microfibrillated cellulose and new nanocomposite materials: a review, Cellulose 17 (2010) 459-494.

[132] H. Wang, D. Li, R. Zhang, Preparation of ultralong cellulose nanofibers and optically transparent nanopapers derived from waste corrugated paper pulp, BioResource 8 (2013) 1374-1384

[133] S. Iwamoto, A.N. Nakagaito, H. Yano, M. Nogi, Optically transparent composites reinforced with plant fiber-based nanofibers, Appl. Phys. A Mater. Sci. Process. 81 (2005) 1109-1112.

[134] B. Wang, M. Sain, Dispersion of soybean stock-based nanofiber in a plastic matrix Polym. Int. 56 (2007) 538-546

135] M.L. Hassan, A.P. Mathew, E.A. Hassan, N.A. El-Wakil, K. Oksman, Nanofibers from bagasse and rice straw: process optimization and properties, Wood Sci. Technol. 46 (2012) 193-205.

[136] Ø. Eriksen, K. Syverud, Ø. Gregersen, The use of microfibrillated cellulose produced from kraft pulp as strength enhancer in TMP paper, Nord. Pulp Pap. Res. J. 23 (2008) 299-304.

[137] T. Lindström, A. Naderi, A. Wiberg, Large scale applications of nanocellulosic materials- a comprehensive review, J. Korea TAPPI. 47 (2015) 5-21.

[138] F. Rol, B. Karakashov, O. Nechyporchuk, M. Terrien, V. Meyer, A. Dufresne, M.N. Belgacem, J. Bras, Pilot-scale twin screw extrusion and chemical pretreatment as an energy-efficient method for the production of nanofibrillated cellulose at high solid content, ACS Sustain. Chem. Eng. (2017)https://doi.org/10.1021/ acssuschemeng.7b00630.

[139] F. Rol, B. Vergnes, N. El Kissi, J. Bras, Nanocellulose production by twin-screw extrusion: simulation of the screw profile to increase the productivity, ACS Sustain. Chem. Eng. (2020)https://doi.org/10.1021/acssuschemeng.9b01913.

[140] M. Bilodeau, J. Spender, A. van Heiningen, Methods for the Production of High Solids Nanocellulose, US20180094383A1, n.d.

[141] A.F. Lourenço, J.A.F. Gamelas, P. Sarmento, P.J.T. Ferreira, Enzymatic nanocellulose in papermaking - the key role as filler flocculant and strengthening agent, Carbohydr. Polym. 224 (2019), 115200.

[142] Q. Tarrés, E. Saguer, M.A. Pèlach, M. Alcalà, M. Delgado-Aguilar, P. Mutjé, The feasibility of incorporating cellulose micro/nanofibers in papermaking processes: the relevance of enzymatic hydrolysis, Cellulose 23 (2016) 1433-1445.

143] R.S.A. Ribeiro, B.C. Pohlmann, V. Calado, N. Bojorge, N. Pereira, Production of nanocellulose by enzymatic hydrolysis: trends and challenges, Eng. Life Sci. (2019)https://doi.org/10.1002/elsc.201800158.

[144] A. Isogai, Y. Kato, Preparation of polyuronic acid from cellulose by TEMPOmediated oxidation, Cellulose 5 (1998) 153-164.

[145] T. Saito, M. Hirota, N. Tamura, S. Kimura, H. Fukuzumi, L. Heux, A. Isogai, Individualization of nano-sized plant cellulose fibrils by direct surface carboxylation using TEMPO catalyst under neutral conditions, Biomacromolecules 10 (2009) 1992-1996.

[146] A.E.J. de Nooy, A.C. Besemer, H. Van Bekkum, Selective oxidation of primary alcohols mediated by nitroxyl radical in aqueous solution. Kinetics and mechanism, Tetrahedron 51 (1995) 8023-8032.

[147] T. Saito, Y. Nishiyama, J.L. Putaux, M. Vignon, A. Isogai, Homogeneous suspensions of individualized microfibrils from TEMPO-catalyzed oxidation of native cellulose, Biomacromolecules 7 (2006) 1687-1691.
[148] T. Saito, S. Kimura, Y. Nishiyama, A. Isogai, Cellulose nanofibers prepared by TEMPO-mediated oxidation of native cellulose, Biomacromolecules 8 (2007) 2485-2491.

[149] E. Espinosa, I. Bascón-Villegas, A. Rosal, F. Pérez-Rodríguez, G. Chinga-Carrasco, A. Rodríguez, PVA/(ligno)nanocellulose biocomposite films. Effect of residual lignin content on structural, mechanical, barrier and antioxidant properties, Int. J. Biol. Macromol. 141 (2019) 197-206.

[150] M. Hirota, N. Tamura, T. Saito, A. Isogai, Oxidation of regenerated cellulose with NaClO2catalyzed by TEMPO and NaClO under acid-neutral conditions, Carbohydr. Polym. 78 (2009) 330-335.

[151] H. Liimatainen, M. Visanko, J.A. Sirviö, O.E.O. Hormi, J. Niinimaki, Enhancement of the nanofibrillation of wood cellulose through sequential periodate-chlorite oxidation, Biomacromolecules 13 (2012) 1592-1597.

[152] R. Peretz, E. Sterenzon, Y. Gerchman, V. Kumar Vadivel, T. Luxbacher, H. Mamane, Nanocellulose production from recycled paper mill sludge using ozonation pretreatment followed by recyclable maleic acid hydrolysis, Carbohydr. Polym. 216 (2019) 343-351.

[153] A. Balea, E. Fuente, M. Concepcion Monte, N. Merayo, C. Campano, C. Negro, A Blanco, Industrial application of nanocelluloses in papermaking: a review of challenges, technical solutions, and market perspectives, Molecules (2020)https://doi. org/10.3390/molecules25030526.

[154] A.F. Lourenço, J.A.F. Gamelas, P. Sarmento, P.J.T. Ferreira, Cellulose micro and nanofibrils as coating agent for improved printability in office papers, Cellulose (2020)https://doi.org/10.1007/s10570-020-03184-9.

[155] F.W. Brodin, Ø.W. Gregersen, K. Syverud, Cellulose nanofibrils: challenges and possibilities as a paper additive or coating material - a review, Nord. Pulp Pap. Res. J. 29 (2014) 156-166.

[156] A.H. Tayeb, E. Amini, S. Ghasemi, M. Tajvidi, Cellulose nanomaterials-binding properties and applications: a review, Molecules. 23 (2018) 1-24.

[157] H. Zhao, X. Wei, Y. Xie, Q. Feng, Preparation of nanocellulose and lignincarbohydrate complex composite biological carriers and culture of heart coronary artery endothelial cells, Int. J. Biol. Macromol. 137 (2019) 1161-1168.

[158] M. Dominic, R. Joseph, P..S. Begum, B.P. Kanoth, J. Chandra, S. Thomas, Green tire technology: effect of rice husk derived nanocellulose (RHNC) in replacing carbon black (CB) in natural rubber (NR) compounding, Carbohydr. Polym. 230 (2019) https://doi.org/10.1016/j.carbpol.2019.115620.

[159] Z. Fang, G. Hou, C. Chen, L. Hu, Nanocellulose-based films and their emerging applications, Curr. Opin. Solid State Mater. Sci. 23 (2019), 100764.

[160] J. Jose, V. Thomas, V. Vinod, R. Abraham, S. Abraham, Nanocellulose based functional materials for supercapacitor applications, J. Sci. Adv. Mater. Devices. 4 (2019) 333-340.

[161] T. Taipale, M. Österberg, A. Nykänen, J. Ruokolainen, J. Laine, Effect of microfibrillated cellulose and fines on the drainage of kraft pulp suspension and paper strength, Cellulose 17 (2010) 1005-1020.

[162] I. González, S. Boufi, M.A. Pèlach, M. Alcalà, F. Vilaseca, P. Mutjé, Nanofibrillated cellulose as paper additive in eucalyptus pulps, Bioresources 7 (2012) 5167-5180.

[163] M. Delgado-Aguilar, I. González, Q. Tarrés, M. Alcalà, M.À. Pèlach, P. Mutjé, Approaching a low-cost production of cellulose nanofibers for papermaking applications, BioResources 10 (2015) 5330-5344.

[164] I. González, F. Vilaseca, M. Alcalá, M.A. Pèlach, S. Boufi, P. Mutjé, Effect of the combination of biobeating and NFC on the physico-mechanical properties of paper, Cellulose 20 (2013) 1425-1435.

[165] X. Hua, T. Owston, M. Laleg, Wet-web strength and Pressability of highly-filled sheets, PaperCon 2011, pp. 851-859.

[166] C. Hii, Ø.W. Gregersen, G. Chinga-Carrasco, Ø. Eriksen, The effect of MFC on the pressability and paper properties of TMP and GCC based sheets, Nord. Pulp Pap. Res. J. 27 (2012) 388-396

[167] K. Yukinori, G. Tomohisa, Y. Manabu, S. Tsuguyuki, I. Akira, Fundamental properties of handsheets containing TEMPO-oxidized pulp in various weight ratios, Nord. Pulp Pap. Res. J. 31 (2016) 248-254.

[168] A. Ämmälä, H. Liimatainen, C. Burmeister, J. Niinimäki, Effect of tempo and periodate-chlorite oxidized nanofibrils on ground calcium carbonate flocculation and retention in sheet forming and on the physical properties of sheets, Cellulose 20 (2013) 2451-2460.

[169] T. Saito, A. Isogai, Wet strength improvement of TEMPO-oxidized cellulose sheets prepared with cationic polymers, Ind. Eng. Chem. Res. 46 (2007) 773-780.

[170] L. Jin, Y. Wei, Q. Xu, W. Yao, Z. Cheng, Cellulose nanofibers prepared from TEMPOoxidation of Kraft pulp and its flocculation effect on kaolin clay, J. Appl. Polym. Sci. 131 (2014) 1-8.

[171] Q.H. Xu, W.G. Li, Z.L. Cheng, G. Yang, M.H. Qin, TEMPO/NaBr/NaClO-mediated surface oxidation of nanocrystalline cellulose and its microparticulate retention system with cationic polyacrylamide, BioResources 9 (2014) 994-1006.

[172] A.F. Lourenço, J.A.F. Gamelas, T. Nunes, J. Amaral, P. Mutjé, P.J. Ferreira, Influence of TEMPO-oxidised cellulose nanofibrils on the properties of filler-containing papers, Cellulose 24 (2017) 349-362.

[173] S.R. Djafari Petroudy, K. Syverud, G. Chinga-Carrasco, A. Ghasemain, H. Resalati, Effects of bagasse microfibrillated cellulose and cationic polyacrylamide on key properties of bagasse paper, Carbohydr. Polym. 99 (2014) 311-318.

[174] O. Li, P. Raj, F.A. Husain, S. Varanasi, T. Rainey, G. Garnier, W. Batchelor, Engineering cellulose nanofibre suspensions to control filtration resistance and sheet permeability, Cellulose 23 (2016) 391-402.

[175] J. Su, W.K.J. Mosse, S. Sharman, W.J. Batchelor, G. Garnier, Effect of tethered and free microfibrillated cellulose (MFC) on the properties of paper composites, Cellulose 20 (2013) 1925-1935.

[176] H. Holik, Handbook for Paper and Board, Deutsche Nationalbibliothek, Ravensburg Germany, 2013. 
[177] N. Lavoine, I. Desloges, B. Khelifi, J. Bras, Impact of different coating processes of microfibrillated cellulose on the mechanical and barrier properties of paper, J. Mater. Sci. 49 (2014) 2879-2893.

[178] S. Mirmehdi, M.L.C. de Oliveira, P.R.G. Hein, M.V. Dias, C.I.G. de L. Sarantópoulos, G.H.D. Tonoli, Spraying cellulose nanofibrils for improvement of tensile and barrier properties of writing \& printing (W\&P) paper, J. Wood Chem. Technol. 38 (2018) 233-245.

[179] K. Syverud, P. Stenius, Strength and barrier properties of MFC films, Cellulose 16 (2009) 75-85.

[180] E.A. Hassan, M.L. Hassan, R.E. Abou-zeid, N.A. El-Wakil, Novel nanofibrillated cellulose/chitosan nanoparticles nanocomposites films and their use for paper coating, Ind. Crop. Prod. 93 (2016) 219-226.

[181] S. Hong, Y. Song, Y. Yuan, H. Lian, H. Liimatainen, Production and characterization of lignin containing nanocellulose from luffa through an acidic deep eutectic solvent treatment and systematic fractionation, Ind. Crop. Prod. 143 (2020), 111913.

[182] T. Jayaramudu, H.-U. Ko, H.C. Kim, J.W. Kim, E.S. Choi, J. Kim, Adhesion properties of poly(ethylene oxide)-lignin blend for nanocellulose composites, Compos. Part B Eng. 156 (2019) 43-50.

[183] P. Samyn, M. Deconinck, G. Schoukens, D. Stanssens, L. Vonck, H. Van den Abbeele, Modifications of paper and paperboard surfaces with a nanostructured polymer coating, Prog. Org. Coatings. 69 (2010) 442-454.

[184] K. Vaezi, G. Asadpour, S.H. Sharifi, Effect of coating with novel bio nanocomposites of cationic starch/cellulose nanocrystals on the fundamental properties of the packaging paper, Polym. Test. 80 (2019).

[185] M. Tajik, H.J. Torshizi, H. Resalati, Y. Hamzeh, Effects of cationic starch in the presence of cellulose nanofibrils on structural, optical and strength properties of paper from soda bagasse pulp, Carbohydr. Polym. 194 (2018) 1-8.

[186] S.S. Nair, J. Zhu, Y. Deng, A.J. Ragauskas, High performance green barriers based on nanocellulose, Sustain. Chem. Process. 2 (2014) 23.

[187] L.A. Harold, Medicinal Dressing Material, US2137169, 1938.

[188] M.J. Robert C, Solution of Water-Soluble Cellulose Ethers, US2340072, 1944.

[189] W.R. Collings, F.C. Peterson, H.C. Kelly, Grease-Proofing Paper, US2235798, 1941.

[190] C. Breen, F. Clegg, S. Thompson, L. Jarnstrom, C. Johansson, Exploring the interactions between starches, bentonites and plasticizers in sustainable barrier coatings for paper and board, Appl. Clay Sci. 183 (2019), 105272.

[191] J. Jung, G.M. Raghavendra, D. Kim, J. Seo, One-step synthesis of starch-silver nanoparticle solution and its application to antibacterial paper coating, Int. J. Biol. Macromol. 107 (2018) 2285-2290.

[192] K. Ren, T. Fei, K. Metzger, T. Wang, Coating performance and rheological characteristics of novel soybean oil-based wax emulsions, Ind. Crop. Prod. 140 (2019) 1-8.

[193] U.V. Brodnjak, Experimental investigation of novel curdlan/chitosan coatings on packaging paper, Prog. Org. Coatings. 112 (2017) 86-92.

[194] C. Laine, A. Harlin, J. Hartman, S. Hyvärinen, K. Kammiovirta, B. Krogerus, H. Pajari, H. Rautkoski, H. Setälä, J. Sievänen, J. Uotila, M. Vähä-Nissi, Hydroxyalkylated xylans - their synthesis and application in coatings for packaging and paper, Ind. Crop. Prod. 44 (2013) 692-704

[195] M.A. Herrera, J.A. Sirviö, A.P. Mathew, K. Oksman, Environmental friendly and sustainable gas barrier on porous materials: Nanocellulose coatings prepared using spin- and dip-coating, Mater. Des. 93 (2016) 19-25.

[196] C. Aulin, M. Gallstedt, T. Lindstrom, Oxygen and oil barrier properties of microfibrillated cellulose films and coatings, Cellulose 17 (2010) 559-574.

[197] A. Miettinen, G. Chinga-Carrasco, M. Kataja, Three-dimensional microstructural properties of nanofibrillated cellulose films, Int. J. Mol. Sci. 15 (2014) 6423-6440.

[198] K.C.C. De Carvalho, S.R. Montoro, M.O.H. Cioffi, H.J.C. Voorwald, Polyhydroxyalkanoates and their nanobiocomposites with cellulose nanocrystals, Des. Appl. Nanostructured Polym. Blends Nanocomposite Syst, 2016https://doi.org/10.1016/B978-0-323-39408-6. 00012-1.

[199] P. Tyagi, L.A. Lucia, M.A. Hubbe, L. Pal, Nanocellulose-based multilayer barrier coatings for gas, oil, and grease resistance, Carbohydr. Polym. 206 (2019) 281-288.

[200] E. Hult, M. Iotti, M. Lenes, Efficient approach to high barrier packaging using microfibrillar cellulose and shellac, Cellulose 17 (2010) 575-586.

[201] C.J. Ridgway, P.A.C. Gane, Constructing NFC-pigment composite surface treatment for enhanced paper stiffness and surface properties, Cellulose 19 (2012) 547-560.

[202] N.A. El-Wakil, N.F. Kassem, M.L. Hassan, Hydroxypropyl cellulose/rice straw oxidized cellulose nanocrystals nanocomposites and their use in paper coating, Ind. Crop. Prod. 93 (2016) 186-192.

[203] X. Zheng, S. Fu, Reconstructing micro/nano hierarchical structures particle with nanocellulose for superhydrophobic coatings, Colloids Surfaces A Physicochem. Eng. Asp. 560 (2019) 171-179.

[204] M. Maliha, M. Herdman, R. Brammananth, M. McDonald, R. Coppel, M. Werrett, P. Andrews, W. Batchelor, Bismuth phosphinate incorporated nanocellulose sheets with antimicrobial and barrier properties for packaging applications, J. Clean. Prod. 246 (2019), 119016

[205] W.T. Luu, D.W. Bousfield, J. Kettle, Application of nano-fibrillated cellulose as a paper surface treatment for inkjet printing, PaperCon 2011, pp. 2222-2233.

[206] M. Imani, A. Ghasemian, M.R. Dehghani-firouzabadi, E. Afra, P.A.C. Gane, O.J. Rojas, Nano-lignocellulose from recycled fibres in coatings from aqueous and ethanolic media: effect of residual lignin on wetting and offset printing quality, Nord. Pulp Pap. Res. J. 34 (2019) 200-210.

[207] A. Pei, N. Butchosa, L.A. Berglund, Q. Zhou, Surface quaternized cellulose nanofibrils with high water absorbency and adsorption capacity for anionic dyes, Soft Matter 9 (2013) 2047-2055.

[208] T. Yanjun, H. Xiulan, L. Dongdong, Preparation Method for Cation Nanocrystalline Cellulose Enhanced Papermaking Surface Sizing Agent, CN105780589, 2016.

[209] P. Neto, Carlos, a R. freire Barros, C. Sofia, D. matos Fernandes, S. Cristina, Aqueous Coating Composition for Use in Surface Treatment of Cellulosic Substrates, WO2011012934 A2, 2011.
[210] Q. Chen, X. Dong, L. Zhou, X. Zheng, J. Wang, P. Wang, Nanostarch surface coating of lightweight coated paper, BioResources 13 (2018) 729-739.

[211] H. Hamada, J. Beckvermit, D. Bousfield, Nanofibrillated cellulose with fine clay as a coating agent to improve print quality, Pap. Conf. Trade Show 2010, Pap. 2010, TAPPI Press, Atlanta, Georgia, USA 2010, pp. 854-880.

[212] T. Nunes, A.F. Lourenço, J.A.f. Gamelas, P.J.T. Ferreira, Cellulose nanofibrils in papermaking-filler retention, wet web resistance and printability, 2nd Int. Conf. Nat. Fibers 2015, pp. 1-5.

[213] H. Hamada, M. Mitsuhashi, Effect of cellulose nanofibers as a coating agent for woven and nonwoven fabrics, Nord. Pulp Pap. Res. J. 31 (2016) 255-260.

[214] M. Ankerfors, T. Lindstrom, H. Song, M. Hoc, Composition for Coating of Printing Paper, US8241756 B2, 2012.

[215] C. Hagiopol, J.W. Johnston, Chemistry of Modern Papermaking, 2011https://doi. org/10.1201/b11011.

[216] Y. Tang, D. Zhou, J. Zhang, X. Zhu, Fabrication and properties of paper coatings with the incorporation of nanoparticle pigments: rheological behavior, Dig. J. Nanomater. Biostructures. 8 (2013) 1699-1710.

[217] W. Koglert, M. Tietz, W.J. Auhorn, Paper and board, 7. Coating of paper and board, Ullmann's Encycl. Ind. Chem 2012, pp. 25-26, https://doi.org/10.1002/14356007. 018_015.

[218] K. Shanmugam, H. Nadeem, C. Browne, G. Garnier, W. Batchelor, Engineering surface roughness of nanocellulose film via spraying to produce smooth substrates, Colloids Surfaces A Physicochem. Eng. Asp. 589 (2020) 1-10.

[219] MarketResearch.biz, Global modified starch market analysis, drivers, restraints, opportunities, threats, trends, applications, and growth forecast to 2027, 2020. https://marketresearch.biz/report/modified-starch-market/.

[220] C.A. de Assis, C. Houtman, R. Phillips, E.M.T. Bilek, O.J. Rojas, L. Pal, M.S. Peresin, H Jameel, R. Gonzalez, Conversion economics of forest biomaterials: risk and financial analysis of CNC manufacturing, Biofuels Bioprod. Biorefin. (2017)https://doi.org/ $10.1002 / \mathrm{bbb} .1782$

[221] C.A. de Assis, M.C. Iglesias, M. Bilodeau, D. Johnson, R. Phillips, M.S. Peresin, E.M.T Bilek, O.J. Rojas, R. Venditti, R. Gonzalez, Cellulose micro- and nanofibrils (CMNF) manufacturing - financial and risk assessment, Biofuels Bioprod. Biorefin. (2018) https://doi.org/10.1002/bbb.1835.

[222] F. Hoeng, A. Denneulin, J. Bras, Use of nanocellulose in printed electronics: a review, Nanoscale (2016)https://doi.org/10.1039/c6nr03054h.

[223] R.M. Kestwal, D. Bagal-Kestwal, B.H. Chiang, 1,3- $\beta$-Glucanase from Vigna aconitifolia and its possible use in enzyme bioreactor fabrication, Int. J. Biol. Macromol. (2011)https://doi.org/10.1016/j.ijbiomac.2011.08.002.

[224] M.J. Farrell, P.J. Hauser, Cationic cotton, reservations to reality, AATCC Rev 13 (2013) 56-63.

[225] J. Bendoraitiene, E. Lekniute-Kyzike, R. Rutkaite, Biodegradation of cross-linked and cationic starches, Int. J. Biol. Macromol. 119 (2018) 345-351.

[226] F. Piccinno, R. Hischier, S. Seeger, C. Som, Predicting the environmental impact of a future nanocellulose production at industrial scale: application of the life cycle assessment scale-up framework, J. Clean. Prod. (2018)https://doi.org/10.1016/j. jclepro.2017.10.226.

[227] R. Arvidsson, D. Nguyen, M. Svanström, Life cycle assessment of cellulose nanofibrils production by mechanical treatment and two different pretreatment processes, Environ. Sci. Technol. (2015)https://doi.org/10.1021/acs.est.5b00888.

[228] CEPI, PRESS RELEASE: Launch of the European Alliance for a Green Recovery, Pap. Online. (2020). http://www.paperonline.org/Green Recovery.

[229] Plastics - The Facts 2019, Plast. Eur. Mark. Res. Gr. Conversio Mark. Strateg. GmbH2019 1-39.

[230] Commission implementing decision of 26 September 2014 establishing the best available techniques (BAT) conclusions, under Directive 2010/75/EU of the European Parliament and of the Council, for the production of pulp, paper and board, Off. J. Eur. Union (2014) 73-126http://www.prtr-es.es/Data/images/ BATpapelEN.pdf. (Accessed 6 May 2020).

[231] Regulation (EC) No 1935/2004 of the European Parliament and of the Council of 27 October 2004 on materials and articles intended to come into contact with food, Off. J. Eur. Union (2004) 14http://data.europa.eu/eli/reg/2004/1935/2009-08-07. (Accessed 6 May 2020).

[232] F. Sen, İ. Uzunsoy, E. Bastürk, M.V. Kahraman, Antimicrobial agent-free hybrid cationic starch/sodium alginate polyelectrolyte films for food packaging materials, Carbohydr. Polym. (2017)https://doi.org/10.1016/j.carbpol.2017.04.079.

[233] M. Ahonen, A. Kahru, A. Ivask, K. Kasemets, S. Kõljalg, P. Mantecca, I.V. Vrček, M.M Keinänen-Toivola, F. Crijns, Proactive approach for safe use of antimicrobial coatings in healthcare settings: opinion of the cost action network AMiCI, Int. J. Environ. Res. Public Health (2017)https://doi.org/10.3390/ijerph14040366.

[234] L. Kong, A. Hasanbeigi, L. Price, Assessment of emerging energy-efficiency technologies for the pulp and paper industry: a technical review, J. Clean. Prod. 122 (2016) $5-28$.

[235] M. Sun, Y. Wang, L. Shi, J.J. Klemeš, Uncovering energy use, carbon emissions and environmental burdens of pulp and paper industry: a systematic review and meta-analysis, Renew. Sust. Energ. Rev. 92 (2018) 823-833.

[236] Mandeep, G.K. Gupta, H. Liu, P. Shukla, Pulp and paper industry-based pollutants, their health hazards and environmental risks, Curr. Opin. Environ. Sci. Heal. 12 (2019) 48-56.

[237] S. Nie, K. Zhang, X. Lin, C. Zhang, D. Yan, H. Liang, S. Wang, Enzymatic pretreatment for the improvement of dispersion and film properties of cellulose nanofibrils, Carbohydr. Polym. (2018)https://doi.org/10.1016/j.carbpol.2017.11.020.

[238] H. Charreau, E. Cavallo, M.L. Foresti, Patents involving nanocellulose: analysis of their evolution since 2010, Carbohydr. Polym. (2020)https://doi.org/10.1016/j. carbpol.2020.116039. 